\title{
Chemical environment of Ag atoms contained in Au-Ag bimetallic catalysts and the generation of the catalytic activity for $\mathrm{CO}$ oxidation
}

\author{
Yasuo Iizuka* \\ Research Institute for Ubiquitous Energy Division, National Institute of Advanced Industrial Science and Technology \\ (AIST), Midorigaoka, Ikeda, Osaka 563-8577, Japan \\ Ryou Inoue, Takumi Miura \\ Department of Chemistry and Materials Technology, Graduate School of Kyoto Institute of Technology, Matsugasaki, \\ Sakyo-ku, Kyoto 606-8585, Japan \\ Nobuyasu Morita, Naoki Toshima \\ Department of Applied Chemistry, Tokyo University of Science Yamaguchi, Daigaku-dori, Sanyo-Onoda, Yamaguchi \\ 756-0884, Japan \\ Tetsuo Honma, Hiroshi Oji \\ Industrial Application Division, Japan Synchrotron Radiation Research Institute (JASRI), Kouto, Sayo-cho, Sayo-gun, \\ Hyogo 679-5198, Japan
}

* To whom correspondence should be addressed: iizuka-fujino@nifty.com $-1-$ 
The chemical environment of $\mathrm{Ag}$ and the catalytic activity for $\mathrm{CO}$ oxidation with $\mathrm{O}_{2}$ of three kinds of bimetallic catalysts, i.e., Ag contaminated Au powder, nanoporous gold (NPG), and Ag-Au colloidal NPs, were examined in order to get insight into the nature of active sites for CO oxidation and the genesis of the catalytic activity for $\mathrm{CO}$ oxidation. Although the preparation method and the morphology of three Au-Ag bimetallic catalysts are largely different one another, the enrichment of $\mathrm{Ag}$ in the surface layer could be observed on any of three Au-Ag bimetallic catalysts, and the Arrhenius plots of the rate constant of $\mathrm{CO}$ oxidation per unit metallic surface area, i.e., $k_{\mathrm{CO} 2}$, determined on three bimetallic catalysts showed almost the same slope. The Ag-K edge EXAS analysis performed on three bimetallic catalysts revealed that the chemical environments of Ag atoms contained in three bimetallic catalysts are similar one another: 1) Ag atoms are surrounded by $\mathrm{Ag}-\mathrm{Ag}$ and by Ag-Au bonds and 2) the $C N$ (coordination number) of $\mathrm{Ag}-\mathrm{Au}$ is larger than that of $\mathrm{Ag}-\mathrm{Ag}$, indicating that $\mathrm{Ag}$ is highly dispersed in the surface layer of three bimetallic catalysts. The $\mathrm{CO}$ oxidation on three bimetallic catalysts is considered to proceed according to the same mechanism on active sites with similar structure consisting of Ag and Au. The extent of the dispersion of $\mathrm{Ag}$ in the surface layer seemed to correlate with the values of $k_{\mathrm{CO} 2}$ determined for the three AgAu bimetallic catalysts.

Au-Ag bimetallic catalysts, CO oxidation, Ag K-edge EXAFS 


\section{Introduction}

Since Haruta and his coworkers first reported that gold nanoparticles (NPs) highly dispersed on $3 \mathrm{~d}$ metal oxides such as $\mathrm{TiO}_{2}, \mathrm{Fe}_{2} \mathrm{O}_{3}$, and $\mathrm{Co}_{3} \mathrm{O}_{4}$ exhibit unexpectedly high catalytic activity for $\mathrm{CO}$ oxidation in the temperature range far below ambient temperature [1,2], many research interests have been paid to elucidate the origin of the extraordinary high catalytic activity of various supported gold catalysts as well as to apply the unique gold catalysis to various practical reactions $[3,4]$. One of the recent streams in the field of gold catalysis is the addition of second metal to gold by which the synergistic effect between $\mathrm{Au}$ and the second metal appears in the activity and in the selectivity for various reactions compared to the corresponding monometallic catalysts. For example, recent literatures on Au-based bimetallic catalysts, such as Au-Pd [5-7], $\mathrm{Au}-\mathrm{Pt}$ [8], $\mathrm{Au}-\mathrm{Cu}$ [9], and Au-Ni [10] report the enhanced activity for glucose oxidation in liquid phase [5], benzyl alcohol oxidation in gas phase [9], ullmann coupling [6], hydrodechlorination [8], and the improved selectivity for hydrogenation of poly nitroarene [10], and the enhanced activity and selectivity for direct synthesis of $\mathrm{H}_{2} \mathrm{O}_{2}$ [7]. However, the reaction mechanism and the nature of active sites in such gold bimetallic catalysts remains unclear so far, should be clarified in order to achieve further advance in the activity as well as in the selectivity in the reactions catalyzed by them [7].

It has been recognized that $\mathrm{Au}-\mathrm{Ag}$ bimetallic catalysts exhibit remarkable synergy effects in various oxidative reactions. For instance, Mou and his group synthesized Au-Ag alloy catalyst supported on mesoporous aluminosilicate and have reported that the catalyst is highly active for $\mathrm{CO}$ oxidation [11-14]. The Au-Ag alloy bimetallic particles have a big size of ca. $30 \mathrm{~nm}$ and mesoporous aluminosilicate is traditionally inert support [11]. As for the mechanism of the evolution of the activity, they proposed a model where the Ag sites play a key role in oxygen activation and the adjacent Au sites act as adsorption site for $\mathrm{CO}$ [13]. Zhang et al. have reported that PVP-protected $\mathrm{Ag}_{\text {core }} / \mathrm{Au}_{\text {shell }}$ bimetallic NPs show higher catalytic activity in aerobic oxidation of glucose in liquid phase than pure Au NPs [15] and they proposed the importance of the charge transfer from Ag to Au in the enhancement of the activity. Bäumer and his group synthesized nanoporous gold (hereafter referred to NPG) with a sponge-like morphology by the selective leaching of silver from a AuAg alloy in $\mathrm{HNO}_{3}$ and reported that NPG exhibits an unexpectedly high activity and selectivity for oxidative coupling of $\mathrm{CH}_{3} \mathrm{OH}$ [16], in addition to the $\mathrm{CO}$ oxidation at ambient pressures and temperatures down to $253 \mathrm{~K}$ [17]. Since NPG contained $0.7 \%$ silver in the bulk and $4.4 \%$ at the surface, they suggested that residual $\mathrm{Ag}$ on the surface of gold sponge is probably responsible for the high catalytic activity for CO oxidation [17].

Ding and his coworkers fabricated NPG by the selective etching from AgAu alloy anode in concentrated $\mathrm{HNO}_{3}$ under applied potential and reported that the sample shows unexpectedly high catalytic activities for CO oxidation [18,19], preferential CO oxidation [20] and for glucose oxidation [21]. They claimed that metallic gold atoms on NPG are the intrinsic active sites where the three kinds of reactions occur [19-21]. As for the role of Ag trapped in the NPG ligaments, they suggested that the residual $\mathrm{Ag}$ atoms do not contribute to the observed activity for the $\mathrm{CO}$ oxidation in the absence and presence of $\mathrm{H}_{2}$ [20] nor for the D-glucose oxidation by performing the experiments where the residual Ag contents were controlled in the range from 0.99 to 50.2 at \% [20] and from 6.8 to $37.9 \mathrm{wt} \%$ [21], respectively, by varying the dealloying time. However, they do not exclude a possibility that Ag species could tune the catalytic properties of neighboring $\mathrm{Au}$ atoms when their content was sufficiently low [20]. Fujita et al. reported recently that a high density of atomic steps and kinks can be observed on the curved surfaces of NPG by spherical-aberration-corrected TEM and proposed from the observation using environmental TEM that the surface defects are active sites for the catalytic oxidation of $\mathrm{CO}$ and residual Ag stabilizes the atomic steps by suppressing $\{111\}$ faceting kinetics [22]. In view of the conflicting reports, the problem whether the residual Ag atoms take part in the catalytic CO oxidation on NPG or not may be needed to examine in connection with the mechanism of the evolution of synergy effect discussed in Au-Ag bimetallic catalysts [17, 19-21, 22]. 
One of the authors previously measured the activity for $\mathrm{CO}$ oxidation of seven samples of unsupported Au powder which were synthesized by evaporating high purity gold metal $(>99.99 \%)$ in inert gas, and of which surfaces were contaminated with various trace amounts of Ag (hereafter referred to $\mathrm{Ag} / \mathrm{Au}$ powder) [23]. Each of the seven samples of $\mathrm{Ag} / \mathrm{Au}$ powder, i.e., $\mathrm{Ag} / \mathrm{Au}-\mathrm{a}$, $\mathrm{Ag} / \mathrm{Au}-\mathrm{b}, \mathrm{Ag} / \mathrm{Au}-\mathrm{c}, \mathrm{Ag} / \mathrm{Au}-\mathrm{d}, \mathrm{Ag} / \mathrm{Au}-03, \mathrm{Ag} / \mathrm{Au}-07$, and $\mathrm{Ag} / \mathrm{Au}-11$, was found to show respective different catalytic activity and XPS surface concentration of Ag. He calculated the values of $k_{\mathrm{CO} 2}$, i.e., the rate constant of the $\mathrm{CO}$ oxidation per unit surface area of the seven samples and plotted them against their surface atomic concentrations of $\mathrm{Ag}$ in order to examine whether the surface $\mathrm{Ag}$ takes part in the oxidation or not. A strong correlation between $k_{\mathrm{CO} 2}$ and the surface concentration of $\mathrm{Ag}$ was found for those samples of $\mathrm{Ag} / \mathrm{Au}$-powder except $\mathrm{Ag} / \mathrm{Au}-03$ [23]. The relationship is reproduced in Figure 1, because the plots are necessary to develop the present work [23]. Whereas, such a correlation could not be recognized in the plots between the values of $k_{\mathrm{CO} 2}$ and the mean particle size of respective samples of $\mathrm{Ag} / \mathrm{Au}$ powder at least for samples with mean particle sizes larger than $80 \mathrm{~nm}$, he concluded that the activity of $\mathrm{Ag} / \mathrm{Au}$ powder was not due to so-called "particle size effect", but "contact interface effect" between Au and Ag in the surface layer [23].

Furthermore, he studied the mechanism of the CO oxidation by using one of the seven samples of $\mathrm{Ag} / \mathrm{Au}$ powder, i.e., $\mathrm{Ag} / \mathrm{Au}-\mathrm{b}$ by means of kinetic measurements combined with the determination of the amount of $\mathrm{CO}_{2}$ produced. The following mechanism was proposed [24]:

$$
\begin{gathered}
\mathrm{O}_{2}+\mathrm{CO} \rightarrow(\mathrm{CO} 3)^{*} \\
\mathrm{CO}, \mathrm{O}_{2} \\
(\mathrm{CO} 3)^{*} \rightarrow \mathrm{CO}_{2}+\mathrm{O} \\
\mathrm{O}+\mathrm{CO} \rightarrow \mathrm{CO}_{2}
\end{gathered}
$$

The reaction proceeds by repeating the following 3 steps: (1) $\mathrm{CO}$ and $\mathrm{O}_{2}$ molecules coadsorb at the contact interface of $\mathrm{Au}$ and $\mathrm{Ag}$ to form $\mathrm{CO} 3$ intermediate; (2) $\mathrm{CO} 3$ intermediate reacts with $\mathrm{CO}$ and/or $\mathrm{O}_{2}$ to produce one $\mathrm{CO}_{2}$ molecule and $\mathrm{O}$ atom; (3) $\mathrm{O}$ atom reacts with $\mathrm{CO}$ to produce another $\mathrm{CO}_{2}[24]$.

One can notice that although three kinds of Au-Ag bimetallic catalysts described above, i.e., AuAg colloid [11-14], NPG [17-20], and Ag/Au powder [23, 24] are largely different one another in the method of preparation, the morphology, and the content of Ag, they exhibit equally remarkable catalytic activity for $\mathrm{CO}$ oxidation. This sort of phenomena is generally called as "synergy effect" or "contact interface effect" or "bimetallic effect", however, the detailed mechanism of the enhancement of the activity has not been known.

The authors consider that the combination of $\mathrm{Au}$ and $\mathrm{Ag}$ atoms particularly tends to produce new catalytically active sites which work for the oxidation of $\mathrm{CO}$ with $\mathrm{O}_{2}$. We examined in this study the catalytic activity for $\mathrm{CO}$ oxidation as well as the chemical environment of $\mathrm{Ag}$ in the above mentioned three kinds of Au-Ag bimetallic catalysts in order to know the chemical composition and the structure of active sites. We expected from the proportional relationship between the surface concentration of $\mathrm{Ag}$ and $k_{\mathrm{CO} 2}$ with respect to the 6 samples of $\mathrm{Ag} / \mathrm{Au}$ powder shown in Figure 1 that a large part of Ag atoms in the surface layer are involved in active sites for $\mathrm{CO}$ oxidation. Therefore, we started the present investigation on the chemical environment of $\mathrm{Ag}$ of the samples of $\mathrm{Ag} / \mathrm{Au}$ powder. Other two kinds of AuAg bimetallic catalysts, i.e., nanoporous gold (NPG) and PVP-protected AgAu alloy NPs were newly prepared. The catalytic activity for CO oxidation of the three kinds of $\mathrm{Au}-\mathrm{Ag}$ bimetallic catalysts was measured in a closed recirculation reaction systems under almost the same reaction condition. The values of $k_{\mathrm{CO} 2}$ were used to compare the activity of the three kinds of Au-Ag bimetallic catalysts in the same unit. The chemical environment of Ag of the three kinds of Au-Ag bimetallic catalysts was examined by Ag K-edge EXAFS analysis under at room temperature and at the atmospheric pressure. 


\section{Experimental}

\subsection{Materials}

\subsubsection{Molten AuAg alloy plate}

Three kinds of molten AuAg alloy plates with a thickness of $0.1 \mathrm{~mm}$ and with nominal molar compositions of $\mathrm{Au}_{90} \mathrm{Ag}_{10}, \mathrm{Au}_{50} \mathrm{Ag}_{50}$, and $\mathrm{Au}_{10} \mathrm{Ag}_{90}$ were purchased from Tsutsumida Kikinzoku Kougyou Co., Ltd. They were used for reference materials for structural analysis around Ag and Au atoms by means of EXAFS measurements at Ag K- and Au L $\mathrm{LIII}_{-}$edges and the subsequent curve fitting analysis.

\subsubsection{Ag contaminated Au powder (Ag/Au powder)}

Since more than $0.05 \mathrm{wt} \%$ of Ag concentration is needed for the EXAFS analysis of the chemical environment of $\mathrm{Ag}$ atoms in the samples of $\mathrm{Ag} / \mathrm{Au}$ powder, five samples of $\mathrm{Ag} / \mathrm{Au}$ powder, i.e., $\mathrm{Ag} / \mathrm{Au}-\mathrm{a}, \mathrm{Ag} / \mathrm{Au}-\mathrm{b}, \mathrm{Ag} / \mathrm{Au}-\mathrm{c}, \mathrm{Ag} / \mathrm{Au}-\mathrm{d}, \mathrm{Ag} / \mathrm{Au}-03$, were selected in the present investigation. Although the results of characterization performed on the seven samples of Ag/Au powder were described minutely in the previous paper [23], Table 1 lists again the data on the five samples of $\mathrm{Ag} / \mathrm{Au}$ powder requisite for the present investigation.

\subsubsection{NPG}

The preparation of NPG was carried out according to the method reported by Ding et al. [18, 19]. A molten $\mathrm{AgAu}$ alloy plate with a composition of $\mathrm{Ag} / \mathrm{Au}=2.5 / 1$ and with a thickness of $0.1 \mathrm{~mm}$ also purchased from Tsutsumida Kikinzoku Kougyou Co.,Ltd was used as anode. A Pt wire (0.25 $\mathrm{mm} \Phi)$ was selected as cathode. The selective dissolution of Ag from anode was performed in concentrated nitric acid under applied potential between $0.4-2.0 \mathrm{~V}$ generated by a variable direct potential controller (R100, Shouwa Denshi Company). Direct current accompanied by the dissolution of Ag was monitored. The dissolution was continued until the current became negligible. The anode residue, i.e., NPG, was washed with first deionized water and then distilled water several times and dried at room temperature before using it as the catalyst for $\mathrm{CO}$ oxidation.

\subsubsection{PVP-protected AuAg colloids and $\mathrm{AuAg} / \mathrm{Al}_{2} \mathrm{O}_{3}$}

Two kinds of PVP-protected AuAg colloids with definite molar ratio of $\mathrm{Au} / \mathrm{Ag}$ were prepared according to the method reported in reference [25]. Briefly, a solution of $\mathrm{HAuCl}_{4}$ and $\mathrm{NaOH}$ in ethanol/water containing PVP was refluxed for $3 \mathrm{~h}$ at $373 \mathrm{~K}$ under $\mathrm{N}_{2}$ to form a colloidal dispersion of Au. The Au colloidal dispersion was filtrated to remove impurities soluble in filtrate via ultrafilter. The solvent remained in the concentrated dispersion was removed by evaporation with a rotary evaporator at $303 \mathrm{~K}$ to obtain PVP-protected Au colloids as powder. After dissolving the $\mathrm{Au}$ colloids into distilled water, a solution of $\mathrm{AgClO}_{4}$ was added and mixed for $24 \mathrm{~h}$ in air at room temperature to form PVP-protected AuAg alloy colloidal dispersion. In this case, the amount of $\mathrm{AgClO}_{4}$ was varied to obtain two kinds of PVP protected AuAg colloids with charged molar ratios of $\mathrm{Au} / \mathrm{Ag}$ as $1 / 1$ and 1/0.25. Extra ions and non-protected nanoparticles were removed by ultra-filtration and washing with ethanol and water. Finally, the concentrated AuAg colloidal dispersion was again evaporated to remove solvent to obtain PVP-protected AuAg alloy colloids as powder. The atomic ratios of $\mathrm{Au} / \mathrm{Ag}$ of the two kinds of PVP protected AuAg colloids prepared were measured by atomic absorption spectroscopy and found to be 1/0.50 and 1/0.2 for those with charged molar ratios of $1 / 1$ and $1 / 0.25$, respectively.

The removal of PVP protecting agent from AuAg colloidal particles needed to measure the catalytic activity for $\mathrm{CO}$ oxidation by their metallic surfaces was performed according to the following manner [26]. The powder of PVP-protected AuAg colloid was dispersed in water with a $\mathrm{pH}$ adjusted around 10 and the powder of $\mathrm{Al}_{2} \mathrm{O}_{3}$ support (JRC ALO6) was suspended into the dispersion. During the sonication of the suspension subsequently performed for $1 \mathrm{hr}$, the colloidal 
particles were adsorbed on the surface of $\mathrm{Al}_{2} \mathrm{O}_{3}$ support. The decantation of the supernatant resulted in the separation of $\mathrm{AuAg}$ colloidal particles adsorbed on the surface of $\mathrm{Al}_{2} \mathrm{O}_{3}$ support from a large part of non-bonded and soluble PVP in water [26]. A small amount of PVP still bonded to the surface of AuAg colloidal particles was eliminated by oxidizing it in circulating $\mathrm{O}_{2}$ at $673 \mathrm{~K}$, which was performed in a closed recirculation reaction system described in the following section. The resultant was used as catalyst, which referred to $\mathrm{AuAg} / \mathrm{Al}_{2} \mathrm{O}_{3}$ hereafter.

\subsection{Catalytic activity measurements}

The catalytic activity for the $\mathrm{CO}$ oxidation of the three kinds of $\mathrm{Au}-\mathrm{Ag}$ bimetallic catalysts was measured by using the closed recirculation reaction system, of which details are described in Supplementary Materials (see "The closed recirculation reaction system and the procedures for the measurement of the catalytic activity for $\mathrm{CO}$ oxidation" and Figure $\mathrm{S} 1$ ). A reaction mixture of CO and $\mathrm{O}_{2}$ with a stoichiometric composition of $\mathrm{CO} / \mathrm{O}_{2}=2 / 1$ was introduced into the circulatory line with a known volume and the product $\mathrm{CO}_{2}$ was condensed in the trap cooled by liquid nitrogen. The specific rate of the $\mathrm{CO}$ oxidation was determined from the rate of decrease of the total pressure. The rate constant of $\mathrm{CO}$ oxidation per unit metallic surface area, i.e., $k_{\mathrm{CO} 2}$, on the three kinds of $\mathrm{Au}-\mathrm{Ag}$ bimetallic catalysts was calculated from the specific rate, the volume of the circulatory line, and the metallic surface area of respective catalysts. In the case of Ag/Au powder and NPG, the metallic surface areas were obtained from their BET surface areas. Whereas, the metallic surface area of $\mathrm{AuAg} / \mathrm{Al}_{2} \mathrm{O}_{3}$ was obtained from the loading of $\mathrm{AuAg}$ and the mean particle size of AuAg colloidal particles, assuming that each particle has semispherical shape.

\section{$2.3 X A S$ (X-ray absorption spectra) measurements and EXAFS (Extended X-ray Absorption Fne Structure) data analysis}

XAS measurements at $\mathrm{Ag} \mathrm{K}$ - and at $\mathrm{Au} \mathrm{L}_{\mathrm{III}}{ }^{-}$edges were performed at BL14B2 at SPring-8, Hyogo, Japan at room temperature and at atmospheric pressure [27, 28]. A double Si(311)-crystal monochromator was employed for energy selection. The XAS spectra of Ag/Au powder at Ag K-edge were measured by fluorescence mode with a 19 elements solid state detector. For the XAS measurements of NPG and molten AuAg alloy at Ag K- and Au $\mathrm{L}_{\mathrm{III}}$ edges, the conversion electron yield method was employed. The measurement of the other materials (PVP-protected AuAg colloidal NPs, $\mathrm{Ag}, \mathrm{Ag}_{2} \mathrm{O}, \mathrm{Au}, \mathrm{Au}(\mathrm{OH})_{3}$, and $\left.\mathrm{KAuCl}_{4}\right)$ at $\mathrm{Ag} \mathrm{K}$ - and $\mathrm{Au} \mathrm{L}_{\mathrm{III}}$ - edges were performed in transmission mode by using gas filled ionization chambers.

The software Athena and Artemis [29] were used for the EXAFS analysis. The EXAFS oscillation functions $\chi(\kappa)$ were extracted by Athena. Then $\chi(\kappa)$ were further analyzed by the curve fitting analysis in Artemis to obtain the structural parameters such as the coordination number $C N$, interatomic distances $R$, the Debye Waller factors $\sigma^{2}$, and the inner potential shifts $\Delta E$. Note that the functions of backscattering amplitude $F(\kappa)$, the phase shift $\varphi(\kappa)$, and mean free path of the photoelectron $\lambda(\kappa)$ calculated by FEFF6 were used in the curve fitting analysis.

\section{Results}

\subsection{Molten AuAg alloy plates (reference)}

Three kinds of molten $\mathrm{AuAg}$ alloy plates, i.e., $\mathrm{Ag}_{90} \mathrm{Au}_{10}, \mathrm{Ag}_{50} \mathrm{Au}_{50}$, and $\mathrm{Ag}_{10} \mathrm{Au}_{90}$, are expected to be homogeneous in composition and structure around both $\mathrm{Ag}$ and $\mathrm{Au}$ atoms corresponding to their respective molar ratios of $\mathrm{Au}$ and Ag. Prior to start the investigation on the chemical environment of Ag contained in three kinds of AgAu bimetallic catalysts, Ag K-edge EXAFS analysis was carried out for these molten $\mathrm{AuAg}$ alloy plates as reference materials for structural analysis. Figure 2 shows the magnitudes of Fourier transform of $k^{3}$-weighted EXAFS oscillation 
extracted from Ag K-edge XAS and the results of curve fitting analysis. The curve fittings performed in the range of $R=1.8-3.2 \AA$ assuming that the first shell of fcc structure around $\mathrm{Ag}$ atom consists of $\mathrm{Ag}$ and $\mathrm{Au}$ atoms according to their molar ratios of $\mathrm{Au}$ and $\mathrm{Ag}$ reproduced well the respective doublet peaks. The doublet peaks of the three AgAu plates vary remarkably according to their molar ratios of $\mathrm{Ag}$ to $\mathrm{Au}$, indicating the significant difference in the chemical environment around Ag. Table 2 summarizes the structural parameters obtained by the curve fitting analysis. It can be seen that the ratios of the coordination number of Ag-Ag to that of Ag-Au are in good agreement with those expected from respective molar ratios of $\mathrm{Ag}$ to $\mathrm{Au}$.

Since the three AgAu alloy plates contain $\mathrm{Au}$ in the amount comparable to that of $\mathrm{Ag}$, the chemical environment of $\mathrm{Au}$ in the AgAu plates were also examined by $\mathrm{Au} \mathrm{L}_{\mathrm{III}}$-edge EXAFS analysis, which are shown in Figure S2 and Table S1 of the Supplementary Materials. It can be seen with respect to the three $\mathrm{AgAu}$ alloy plates that the ratios of the coordination number of $\mathrm{Au}-\mathrm{Ag}$ to that of $\mathrm{Au}-\mathrm{Au}$ almost reflect those expected from their molar ratios of $\mathrm{Au}$ to $\mathrm{Ag}$ likewise in the case of the chemical environment of Ag. We consider on the basis of these results that we can examine the chemical environment around both $\mathrm{Ag}$ and $\mathrm{Au}$ atoms in the $\mathrm{Au}-\mathrm{Ag}$ bimetallic catalysts targeted in this study by using the EXAFS analysis.

\subsection{Ag contaminated Au powder (Ag/Au powder)}

Table 1 lists the BET surface area, ICP bulk, and XPS surface composition previously determined on the five samples of $\mathrm{Ag} / \mathrm{Au}$ powder. In order to get the information about the chemical environment of $\mathrm{Ag}$ contained in the samples, the results of the characterization listed in Table 1 were reexamined. The values of surface Ag atomic concentrations estimated by XPS are far high compared to those expected from their bulk contents particularly in the samples of Ag/Au-b and $\mathrm{Ag} / \mathrm{Au}-\mathrm{c}$, indicating that the enrichment of $\mathrm{Ag}$ takes place in the surface layer of these five samples.

The extents of the surface enrichment of Ag were estimated from the results of characterization listed in Table 1. The results are summarized in Table 3 . The $3^{\text {rd }}$ column lists the mean particle diameter of the $\mathrm{Ag} / \mathrm{Au}$ powder calculated from their BET surface area and the mean density. The amount of Ag contained in the surface layer of the samples was then estimated by using the surface atomic concentrations of Au and Ag measured by XPS. It was necessary to estimate the depth of surface layer from which the photoelectrons bring about the information. According to ref. [30], the sampling depth of $\mathrm{Au} 4 \mathrm{f}_{7 / 2}$ photoelectron excited by $\mathrm{Mg} \mathrm{K \alpha} \mathrm{X}$-rays depends upon the emission angle of the electrons relative to the sample plane. In the case where the detector was placed normal to the surface plane, the mean escape depth of photoelectrons is given to be $10.6 \AA$, which corresponds to 3.7 surface layers from atomic radius of $\mathrm{Au}$, i.e., $1.44 \AA$.

The $6^{\text {th }}$ column of Table 3 lists the values of ratios 1 and 2, both of which were calculated to estimate the extent of surface enrichment of $\mathrm{Ag}$ in the samples of $\mathrm{Ag} / \mathrm{Au}$ powders. The former is the ratio of the amount of $\mathrm{Ag}$ contained in the 3.7 surface layers obtained from the BET surface area and the XPS surface atomic concentration of Ag to the whole amount of Ag calculated on the basis of the results of ICP bulk analysis. The latter is the ratio of the number of Ag and Au atoms contained in the 3.7 surface layers to those contained in the whole bulk. With respect to the samples of $\mathrm{Ag} / \mathrm{Au}-\mathrm{b}$ and $\mathrm{Ag} / \mathrm{Au}-\mathrm{c}$, however, the calculated amounts of $\mathrm{Ag}$ in 3.7 surface layers far exceed those contained in the whole bulk, indicating that photoelectrons bring about the information from surface layers with much smaller depth than 3.7. This might be due to the fact that almost all photoelectrons emitted from the surface of the particles of $\mathrm{Ag} / \mathrm{Au}$ powder and detected as signal have directions not normal with respect to the surface plane, because the shape of particles are almost spherical with various sizes and have irregularly curved surfaces. Table 3 therefore presents the values of ratio 1 and ratio 2 calculated on the assumption that the mean escape depths of $A u 4 f_{7 / 2}$ photoelectrons were 2.7 and 1.7 surface layers. Although the value of ratio 1 still exceeded 1 in the case of the sample of $\mathrm{Ag} / \mathrm{Au}-\mathrm{c}$ having extremely small content of $\mathrm{Ag}$, it would be most reasonable to estimate that the depth of surface layer from which the photoelectrons bring about the 
information is 1.7 subsurface layers of each samples of $\mathrm{Ag} / \mathrm{Au}$ powder, because the estimation on 0.7 subsurface layers is unreasonable. In fact, a strong enrichment of $\mathrm{Ag}$ in the topmost atomic layer has been reported by Kim et al. by measuring SERS (Surface-Enhanced Raman Scattering) spectra of 2,6 -Dimethylphenyl Isocyanide adsorbed on $\mathrm{Au} / \mathrm{Ag}$ alloy nanoparticles with a nominal composition of $\mathrm{Au}_{0.95} \mathrm{Ag}_{0.05}$ [31] and recently by Déronzier et al. by measuring LEIS (Low-Energy Ion scattering) of nanoforms catalysts with nominal compositions of $\mathrm{Ag}_{2} \mathrm{Au}_{98}, \mathrm{Ag}_{4} \mathrm{Au}_{96}$, and $\mathrm{Ag}_{6} \mathrm{Au}_{94}[32]$.

According to the values of ratio 1 in the $8^{\text {th }}$ column of Table 3, the extent of the enrichment of Ag in the surface layer differs from one sample to another. The extent of the surface enrichment of $\mathrm{Ag}$ is in the following order:

$$
\mathrm{Ag} / \mathrm{Au}-\mathrm{c}>\mathrm{Ag} / \mathrm{Au}-\mathrm{b}>\mathrm{Ag} / \mathrm{Au}-\mathrm{d}>\mathrm{Ag} / \mathrm{Au}-\mathrm{a}>\mathrm{Ag} / \mathrm{Au}-03 .
$$

In the case of $\mathrm{Ag} / \mathrm{Au}-\mathrm{c}$, the content of $\mathrm{Ag}$, i.e., $0.038 \mathrm{wt} \%$ is the smallest among the five samples of $\mathrm{Ag} / \mathrm{Au}$ powder. However, the extent of the enrichment of $\mathrm{Ag}$ in the surface layer is the largest, suggesting that almost all $\mathrm{Ag}$ contained in $\mathrm{Ag} / \mathrm{Au}-\mathrm{c}$ exists on near top two surface layers. As for the catalytic activity for $\mathrm{CO}$ oxidation shown in Figure 1, the value of $k_{\mathrm{CO} 2}$ of $\mathrm{Ag} / \mathrm{Au}-\mathrm{c}$ is slightly larger compared to those of $\mathrm{Ag} / \mathrm{Au}-\mathrm{b}$ and $\mathrm{Ag} / \mathrm{Au}-\mathrm{d}$. Importantly, both of the latter two samples contain larger amount of Ag but their extents of the surface enrichment of Ag are smaller than that of $\mathrm{Ag} / \mathrm{Au}-\mathrm{c}$. This indicates that $\mathrm{Ag}$ atoms exposed on near top surface layers of $\mathrm{Ag} / \mathrm{Au}$ powder work as active sites for $\mathrm{CO}$ oxidation.

In the case of $\mathrm{Ag} / \mathrm{Au}-03$, the content of $\mathrm{Ag}$ is larger by ca. 7 times compared to that of $\mathrm{Ag} / \mathrm{Au}-\mathrm{c}$. However, the extent of the enrichment of Ag in the surface layer is the smallest, indicating that a large part of Ag exists in the bulk and does not contribute to the oxidation of $\mathrm{CO}$. Although the XPS surface concentration of $\mathrm{Ag}$ in $\mathrm{Ag} / \mathrm{Au}-03$ is almost the same with that of $\mathrm{Ag} / \mathrm{Au}-\mathrm{c}$, the value of $k_{\mathrm{CO} 2}$ of $\mathrm{Ag} / \mathrm{Au}-03$ is smaller by two orders of magnitude compared with that of $\mathrm{Ag} / \mathrm{Au}-\mathrm{c}$ as shown in Figure 1. The chemical environment of $\mathrm{Ag}$ in the surface layer of $\mathrm{Ag} / \mathrm{Au}-03$ should differ from that of $\mathrm{Ag}$ in the surface layer of $\mathrm{Ag} / \mathrm{Au}-\mathrm{c}$. With respect to the sample of $\mathrm{Ag} / \mathrm{Au}-\mathrm{a}$, the contents of $\mathrm{Ag}$ in the bulk and in the surface layer as well as the value of BET specific surface area are larger by one order of magnitude than those of the other four samples of $\mathrm{Ag} / \mathrm{Au}$ powder. Judging from the surface concentration of $\mathrm{Ag}$, i.e., 40.9 atomic $\%$, the values of ratio 1 and ratio 2, $\mathrm{Ag} / \mathrm{Au}-\mathrm{a}$ may have a core-shell structure in which Ag Au alloy shell covers Au rich core.

Next EXAFS analysis at Ag K-edge was applied to the five samples of Ag/Au powder to examine the chemical environment of Ag and to obtain some information about the structure of active sites for $\mathrm{CO}$ oxidation. Although almost all the $\mathrm{Ag}$ atoms contained in $\mathrm{Ag} / \mathrm{Au}-\mathrm{c}$ are expected to exist at the region near to surface layer, the content of Ag is very small. The Ag/Au-b powder contains the $\mathrm{Ag}$ atoms about three times larger than that of $\mathrm{Ag} / \mathrm{Au}-\mathrm{c}$. The extent of the surface enrichment of $\mathrm{Ag}$ is the second among the five samples of $\mathrm{Ag} / \mathrm{Au}$ powder. The value of $k_{\mathrm{CO} 2}$ of $\mathrm{Ag} / \mathrm{Au}-\mathrm{b}$ and that of $\mathrm{Ag} / \mathrm{Au}-\mathrm{c}$ are almost the same as presented in Figure 1.These mean that a significant part of Ag atoms contained in $\mathrm{Ag} / \mathrm{Au}-\mathrm{b}$ participate with the active sites for $\mathrm{CO}$ oxidation. Accordingly, $\mathrm{Ag} / \mathrm{Au}-\mathrm{b}$ was selected as a representative sample for the EXAFS analysis of the chemical environment of Ag. Figure 3 shows the magnitude of Fourier transform of $k^{3}$-weighted EXAFS oscillation extracted from Ag K-edge XAS of Ag/Au-b and the results of the curve fitting analysis performed in the range of $R=1.8-3.2 \AA$. That of $\mathrm{Ag}_{2} \mathrm{O}$ is also drawn in the figure.

Figure 4 presents the model structure around $\mathrm{Ag}$ atom used at the start of the curve fitting analysis of Ag/Au-b. In order to model Ag atoms dispersed and exposed on the top surface layer of Ag contaminated Au powder, $6 \mathrm{Ag}$ atoms were replaced with $\mathrm{Au}$ and $4 \mathrm{Ag}$ atoms were removed from the fcc unit cell of Ag metal. The type of bonds around Ag and the structural parameters determined by the curve fitting analysis for Ag/Au-b are summarized in Table 4 together with those for the other four samples of $\mathrm{Ag} / \mathrm{Au}$ powder.

The $C N$ s of $\mathrm{Ag}-\mathrm{Ag}$ and $\mathrm{Ag}-\mathrm{Au}$ with respect to $\mathrm{Ag} / \mathrm{Au}-\mathrm{b}$ are near to those of the model structure. Since Table 3 suggests that a large part of $\mathrm{Ag}$ in $\mathrm{Ag} / \mathrm{Au}-\mathrm{b}$ and $\mathrm{Ag} / \mathrm{Au}-\mathrm{c}$ would be contained near top two surface layers, they may exist in the chemically unsaturated environment like that illustrated in 
Figure 4. Judging from the results for $\mathrm{Ag} / \mathrm{Au}-\mathrm{a}, \mathrm{Au} / \mathrm{Au}-\mathrm{d}$, and $\mathrm{Ag} / \mathrm{Au}-03$ in Table 3, a significant part of Ag atoms may exist in the bulk. However, Figure 4 was used at the start of the curve fitting analysis of these samples. The obtained results may reflect the mean $C N \mathrm{~s}$ of saturated $\mathrm{Ag}$ atoms in the bulk and those unsaturated in the surface layer. The structural parameters obtained by the analysis in Table 4 also suggest that 1) Ag atoms are surrounded by $\mathrm{Ag}$ and $\mathrm{Au}$ atoms and 2) the $C N$ of $\mathrm{Ag}$ - $\mathrm{Au}$, i.e., ca. 6-10 are larger than those of $\mathrm{Ag}-\mathrm{Ag}$, i.e., 2-3, indicating that the $\mathrm{Ag}$ atoms are dispersed atomically by forming the bond with $\mathrm{Au}$ in the surface layer and in the bulk of the $\mathrm{Au}$ powder. Although the amounts of Ag contained in the samples of Ag/Au powder are much lower than $10 \mathrm{at} \%$, the $C N$ of $\mathrm{Ag}$-Ag in all of the samples are larger than that of $\mathrm{Ag}_{10} \mathrm{Au}_{90}$ alloy plate, in which Ag atoms are dissolved in Au metal homogeneously. Accordingly, trace amounts of Ag were dispersed not by losing Ag-Ag bonds perfectly but by maintaining Ag-Ag bonds slightly in the surface layer and the bulk of the Au powder

\subsection{Nanoporous gold (NPG)}

Figure 5 shows the variation of the current with time observed during the preparation of the NPG by the anode etching of $\mathrm{AgAu}$ alloy $(\mathrm{Ag} / \mathrm{Au}=2.5 / 1)$. The weight of $\mathrm{Ag}$ etched from $\mathrm{AuAg}$ alloy was calculated from the current integrated for 90 min by using Faraday's law and compared with the weight loss of the alloy after the etching and the nominal content of Ag in the alloy before the etching. The results are summarized in Table 5(a). Three kinds of Ag weight agree well with each other, indicating that the current was solely due to $\mathrm{Ag}^{+}$ions dissolved. Therefore, it can be said that Figure 5 depicts the process of the formation of the NPG by selective etching of Ag from the alloy. The current increased at first rapidly, reached a maximum value and then decreased exponentially to almost zero. The initial increase and the following decrease of the current must be due to the increase in the inner surface area of the alloy accompanied by the etching of Ag and the decrease in the amount of Ag left in the alloy, respectively.

Table 5(b) presents the results of a series of characterization performed on NPG. It is notable that the BET surface area of the NPG reached $62 \mathrm{~m}^{2} / \mathrm{g}$. Although the current reached to be negligible at $90 \mathrm{~min}$ as shown in Figure 5, ICP analysis showed that small amount of Ag remained. The amount could not be decreased by prolonging the etching time for further $60 \mathrm{~min}$. The amount of Ag in the surface layer was estimated from its BET surface area and the surface atomic concentration of Ag by XPS on the simple assumption that XPS data gave merely the atomic $\%$ of top surface layers. The estimated amount of $\mathrm{Ag}$ in the surface layer was $1.3 \mathrm{wt} \%$. The estimation is near to the ICP bulk content of Ag i.e., $1.5 \mathrm{wt} \%$, suggesting that the enrichment of Ag occurred also near to the top surface layers of NPG.

Figure 6 shows the first order plots of the decrease of the reaction mixture of $\mathrm{CO}$ and $\mathrm{O}_{2}$ with an initial pressure of ca. $2.66 \mathrm{kPa}$ introduced to fresh NPG at room temperature, $283 \mathrm{~K}, 273 \mathrm{~K}, 263 \mathrm{~K}$, and $243 \mathrm{~K}$. Although the plots deviate downward and upward from initial linear line with time, the amounts of $\mathrm{CO}_{2}$ produced agreed well with $2 / 3$ of those of the reaction mixture consumed at respective temperatures (Table S2 in the Supplementary Materials), indicating that the reaction proceeded catalytically. The half times of the initial pressure of the reaction mixture were ca. $5 \mathrm{~min}$ at room temperature and ca. $8 \mathrm{~min}$ at $243 \mathrm{~K}$, showing that 1 ) the NPG exhibits high catalytic activity for $\mathrm{CO}$ oxidation in the low temperature range and 2) the apparent activation energy for the oxidation is quite low. These features were almost the same with those observed on Ag/Au-b reported previously [24]. Therefore, the rate constants of $\mathrm{CO}$ oxidation per unit metallic surface area of the NPG, i.e., $k_{\mathrm{CO} 2}$, were calculated from the slope of first order plots at each temperature and compared with those measured on Ag/Au-b [24]. The results are presented in Figure 7.

Although the NPG and Ag/Au-b are entirely different in the morphology and in the method of preparation, the Arrhenius plots of $k_{\mathrm{CO} 2}$ of both catalysts show almost the same slope. The apparent activation energies for the catalysis of $\mathrm{CO}$ oxidation $\left(E_{\mathrm{a}}\right)$, were calculated to be $6.6 \mathrm{~kJ} / \mathrm{mol}$ and 5.2 $\mathrm{kJ} / \mathrm{mol}$ for the NPG and Ag/Au-b, respectively. This suggests that the mechanism of the catalysis of 
$\mathrm{CO}$ oxidation on NPG is similar to that reported on Ag/Au-b [24]. On the other hand, the values of $k_{\mathrm{CO} 2}$ of the NPG are nearly one order of magnitude smaller compared to those of Ag/Au-b as shown in Figure 7. Since XPS surface atomic compositions of NPG $(8.5 \%)$ is comparable to that of $\mathrm{Ag} / \mathrm{Au}$ powder $(10.8 \%)$, the value of $k_{\mathrm{CO} 2}$ of NPG at $273 \mathrm{~K}$ was added in Figure 1 . It can be seen that the plot of $k_{\mathrm{CO} 2}$ of the NPG deviates downward from linear line interpolating those of the samples of $\mathrm{Ag} / \mathrm{Au}$ powder except for $\mathrm{Ag} / \mathrm{Au}-03$.

Next, the chemical environment of residual Ag atoms in the NPG was investigated and compared with those enriched in the surface layer of the samples of $\mathrm{Ag} / \mathrm{Au}$ powder. Figure $\mathrm{S} 3$ in Supplementary Materials shows the magnitude of Fourier transform of $k^{3}$-weighted EXAFS oscillation extracted from Ag K-edge XAS of the NPG and the results of the curve fitting analysis performed in the range of $R=1.8-3.2 \AA$. The structural parameters determined by the analysis are summarized in Table 6. Similar to the case of five samples of $\mathrm{Ag} / \mathrm{Au}$ powder, Ag atoms are surrounded by $\mathrm{Ag}$ and $\mathrm{Au}$ atoms and the $\mathrm{CN}$ of $\mathrm{Ag}-\mathrm{Au}$ is larger than that of $\mathrm{Ag}-\mathrm{Ag}$, indicating that $\mathrm{Ag}$ is dispersed atomically by forming the bonds with $\mathrm{Au}$ in the surface layer of the NPG. The content of $\mathrm{Ag}$ in the NPG is only $1.5 \mathrm{wt} \%$. However, the $\mathrm{CN}$ of $\mathrm{Ag}-\mathrm{Ag}$ is larger than that of $\mathrm{Ag}_{10} \mathrm{Au}_{90}$ alloy metal plate, indicating that residual $\mathrm{Ag}$ atoms maintain $\mathrm{Ag}-\mathrm{Ag}$ bond in the surface layer of the NPG likewise in the case of the samples of Ag/Au powder. Accordingly, the chemical environment of $\mathrm{Ag}$ in the NPG is probably similar to that in five samples of $\mathrm{Ag} / \mathrm{Au}$ powder.

\section{4 $\mathrm{AgAu}$ alloy colloids and those supported on $\mathrm{Al}_{2} \mathrm{O}_{3}$}

After eliminating a small amount of PVP bonded to $\mathrm{AuAg}$ colloidal particles adsorbed on $\mathrm{Al}_{2} \mathrm{O}_{3}$ support by oxidizing treatment, the catalytic activity was measured for $\mathrm{CO}$ oxidation of two samples of $\mathrm{AuAg} / \mathrm{Al}_{2} \mathrm{O}_{3}$ with different nominal $\mathrm{Au} / \mathrm{Ag}$ compositions, i.e., 1/1 and 1/0.25, (hereafter, will be referred to $\mathrm{AuAg} / \mathrm{Al}_{2} \mathrm{O}_{3}(1 / 1)$ and $\mathrm{AuAg} / \mathrm{Al}_{2} \mathrm{O}_{3}(1 / 0.25)$, respectively). Figure 8 presents HAADF-STEM images of both samples of $\mathrm{AuAg} / \mathrm{Al}_{2} \mathrm{O}_{3}$ and respective $\mathrm{AuAg}$ particle size distribution diagrams, which were taken after the catalytic activity measurements for $\mathrm{CO}$ oxidation. Particles of AuAg colloid can be clearly distinguished as white spots from dark $\mathrm{Al}_{2} \mathrm{O}_{3}$ support. The mean particle sizes of $\mathrm{AuAg}$ were estimated to be $4.8 \mathrm{~nm}$ and $6.9 \mathrm{~nm}$ for $\mathrm{Au} / \mathrm{Ag}=1 / 1$ and 1/0.25, respectively.

Both samples of $\mathrm{AuAg} / \mathrm{Al}_{2} \mathrm{O}_{3}$ exhibited the activity around room temperature likewise the samples of Ag/Au powder and the NPG, although they are supported catalysts unlike the other $\mathrm{Au}-\mathrm{Ag}$ bimetallic catalysts. It has been well known that $\mathrm{Au}$ catalysts highly dispersed on transition and reducible metal oxides such as $\mathrm{Fe}_{2} \mathrm{O}_{3}, \mathrm{NiO}$, and $\mathrm{Co}_{3} \mathrm{O}_{4}$ exhibit enormously high catalytic activity for the low temperature $\mathrm{CO}$ oxidation, which are ascribed to contact interface effect and particle size effect of gold [33, 34]. However, since $\mathrm{Al}_{2} \mathrm{O}_{3}$ is the oxide of typical element and the insulator, it should be inert support for the catalytic oxidation of $\mathrm{CO}$ at least near room temperature. Accordingly, the catalytic activity observed on both samples of $\mathrm{AuAg} / \mathrm{Al}_{2} \mathrm{O}_{3}$ is not probably due to the contact interface effect between $\mathrm{AuAg}$ colloidal $\mathrm{NPs}$ and $\mathrm{Al}_{2} \mathrm{O}_{3}$ support. Furthermore, the so-called particle size effect of gold has been said to appear when the size of gold becomes smaller than $5 \mathrm{~nm}$. The mean sizes of AuAg NPs in the $\mathrm{AuAg} / \mathrm{Al}_{2} \mathrm{O}_{3}$ samples are near or larger than $5 \mathrm{~nm}$, where the particle size effect of $\mathrm{Au}$ does not appear $[33,34]$. Consequently, the catalytic activity observed on $\mathrm{AuAg} / \mathrm{Al}_{2} \mathrm{O}_{3}$ can be ascribed to the surface of the AuAg NPs only.

On this ground, we calculated the values of $k_{\mathrm{CO} 2}$, i.e., the catalytic activity for $\mathrm{CO}$ oxidation per unit metallic surface area of the $\mathrm{AuAg}$ NPs on both $\mathrm{AuAg} / \mathrm{Al}_{2} \mathrm{O}_{3}$ samples and compared them with those of Ag/Au-b and the NPG in Figure 7. The metallic surface areas of the AuAg NPs of the two $\mathrm{AuAg} / \mathrm{Al}_{2} \mathrm{O}_{3}$ samples were calculated from their respective mean sizes and loadings, i.e., $3 \mathrm{wt} \%$, assuming that each AuAg NPs has semispherical shape. The Arrhenius plots of $k_{\mathrm{CO} 2}$ of $\mathrm{AuAg} / \mathrm{Al}_{2} \mathrm{O}_{3}(1 / 0.25)$ almost overlap and show almost the same slope with those of $\mathrm{Ag} / \mathrm{Au}-\mathrm{b}$ and the NPG.; the value of $E_{\mathrm{a}}$, was calculated to be $6.9 \mathrm{~kJ} / \mathrm{mol}$ for $\mathrm{AuAg} / \mathrm{Al}_{2} \mathrm{O}_{3}(1 / 0.25)$. Both the structure of active sites and the mechanism of the catalytic oxidation of $\mathrm{CO}$ on the $\mathrm{AuAg} / \mathrm{Al}_{2} \mathrm{O}_{3}(1 / 0.25)$ 
might be similar to those on Ag/Au-b and on the NPG.. On the other hand, the sample of $\mathrm{AuAg} / \mathrm{Al}_{2} \mathrm{O}_{3}(1 / 1)$ showed lower activity and somewhat larger slope compared to $\mathrm{AuAg}$ $/ \mathrm{Al}_{2} \mathrm{O}_{3}(1 / 0.25)$; the value of $E_{\mathrm{a}}$ for $\mathrm{AuAg} / \mathrm{Al}_{2} \mathrm{O}_{3}(1 / 1)$ was calculated to be $13.3 \mathrm{~kJ} / \mathrm{mol}$. The structure of active sites on the surface of $\mathrm{AuAg} / \mathrm{Al}_{2} \mathrm{O}_{3}(1 / 1)$ may differ slightly from those on $\mathrm{AuAg}$ $/ \mathrm{Al}_{2} \mathrm{O}_{3}(1 / 0.25)$.

Thus the chemical environments of Ag atoms in the AuAg alloy colloids were investigated by EXAFS analysis. In this case, two kinds of as prepared PVP-protected AuAg alloy NPs with nominal compositions of $\mathrm{Au} / \mathrm{Ag}=1 / 1$ and 1/0.25, hereafter referred to $\operatorname{AuAg}(1 / 1)$ and $\operatorname{AuAg}(1 / 0.25)$, respectively, were used as samples in order to obtain XAS spectra with signal-to-noise ratio as high as possible. Although the mean particle sizes of $\operatorname{AuAg}(1 / 1)$ and $\operatorname{AuAg}(1 / 0.25)$, i.e., $4.2 \mathrm{~nm}$ and 4.6 $\mathrm{nm}$, were somewhat smaller than those of $\mathrm{AuAg} / \mathrm{Al}_{2} \mathrm{O}_{3}(1 / 1)$ and $\mathrm{AuAg} / \mathrm{Al}_{2} \mathrm{O}_{3}(1 / 0.25)$, we assumed that the composition and the structure of $\mathrm{AuAg}(1 / 1)$ and $\mathrm{AuAg}(1 / 0.25)$ are almost the same as those of $\mathrm{AuAg} / \mathrm{Al}_{2} \mathrm{O}_{3}(1 / 1)$ and $\mathrm{AuAg} / \mathrm{Al}_{2} \mathrm{O}_{3}(1 / 0.25)$, respectively. Since both samples of $\mathrm{AuAg}(1 / 1)$ and $\mathrm{AuAg}(1 / 0.25)$ contain $\mathrm{Au}$ and $\mathrm{Ag}$ at comparable concentrations, EXAFS analysis at $\mathrm{Au} \mathrm{L}_{\mathrm{III}}$-edge were also performed in addition to that at Ag K-edge. Figure 9 presents the magnitude of Fourier transform of $k^{3}$-weighted EXAFS oscillation extracted from the XAS of AuAg(1/0.25) at (a) Au $\mathrm{L}_{\mathrm{III}}$-edge and (b) Ag K-edge, together with the results of the curve fitting analysis performed in the range of $R=1.95-3.2 \AA$ and $1.6-3.2 \AA$ for (a) and (b), respectively. Those of $A u A g(1 / 1)$ are shown in Figure S4 in Supplementary Materials. The structural parameters of $\mathrm{AuAg}(1 / 1)$ and $\mathrm{AuAg}(1 / 0.25)$ determined by the curve fitting analyses of $\mathrm{Au} \mathrm{L}_{\mathrm{III}}-$ and $\mathrm{Ag} \mathrm{K}$-edges are summarized in Table 7 (a) and (b), respectively.

In the curve fitting analysis of $\mathrm{Au} \mathrm{L}_{\mathrm{III}}$-edge EXAFS, the peak observed at $R=1.9-3.2 \AA$ on both samples of $\mathrm{AuAg}(1 / 1)$ and $\mathrm{AuAg}(1 / 0.25)$ could well be fitted by the fcc model structure in which only the $\mathrm{Au}$ atoms are in the $1^{\text {st }}$ shell around the central Au atom as presented in Table 6(a): the model which contains Ag atoms in the 1st shell could not reproduce the peaks at all. Since 1) the concentrations of $\mathrm{Ag}$ in both samples of $\mathrm{AuAg}(1 / 1)$ and $\mathrm{AuAg}(1 / 0.25)$ were determined to be $1 / 0.5$ and 1/0.2, respectively, as mentioned in the experimental section, and 2) EXAFS analysis of the alloy metal plates of $\mathrm{Au}_{50} \mathrm{Ag}_{50}$ and $\mathrm{Au}_{90} \mathrm{Ag}_{10}$ shows that $\mathrm{Au}-\mathrm{Ag}$ bonds exist in addition to $\mathrm{Au}-\mathrm{Au}$ ones in the $1^{\text {st }}$ shell as presented in Table 2, the distributions of $\mathrm{Ag}$ around $\mathrm{Au}$ atoms in two samples of $\mathrm{AuAg}(1 / 1)$ and $\mathrm{AuAg}(1 / 0.25)$ are clearly inhomogeneous. On the other hand, in the analysis of Ag K edge EXAFS, the peak observed in the range of $R=1.8-3.2 \AA$ of both samples of $\mathrm{AuAg}(1 / 1)$ and $\mathrm{AuAg}(1 / 0.25)$ are well fitted by the model in which $1^{\text {st }}$ shell around $\mathrm{Ag}$ atoms contains both $\mathrm{Ag}$ and $\mathrm{Au}$ atoms likewise in the case of the Ag/Au powder and the NPG as presented in Table 6(b). Since $\mathrm{Au}$ and $\mathrm{Ag}$ can form perfect solid solution at equilibrium as shown by the EXAFS analysis of AuAg alloy metal plates with different molar compositions, the structure and composition of both samples of $\mathrm{AuAg}(1 / 1)$ and $\mathrm{AuAg}(1 / 0.25)$ can be said to have not attained to the equilibrium state. Since they were prepared by impregnating PVP-protected Au colloidal particles having comparatively large mean particle sizes of ca. 4-5 nm with the solution of $\mathrm{AgClO}_{4}$, it is probable that $\mathrm{Ag}$ dissolved into the surface layer of colloidal particles of $\mathrm{Au}$ to form $\mathrm{AuAg}$ alloy shell which covers the Au core. In fact, Zhang and his coworkers described that Ag/Au bimetallic nanoparticles posses the structure with Au-rich core and Ag-rich shell especially when Au NPs are large in particle size [35].

In order to examine the validity of the model of Au core and AuAg shell structure, we made the model Au core and AuAg shell structures of colloidal particle of $\mathrm{AuAg}(1 / 1)$ and $\mathrm{AuAg}(1 / 0.25)$ based on their mean diameter and atomic concentrations of $\mathrm{Au}$ and $\mathrm{Ag}$, in both of which $\mathrm{Ag}$ atoms were distributed in top two surface layers, and then calculated the mean coordination numbers around $\mathrm{Au}$ and $\mathrm{Ag}$ atoms [36,37]. Table 8 presents the $C N$ s calculated from the model structure and those obtained from the EXAFS analysis. The $C N$ s of $\mathrm{Au}$ and $\mathrm{Ag}$ atoms calculated from the model can be said to reflect the feature of those observed on both samples of $\operatorname{AuAg}(1 / 1)$ and $\operatorname{AuAg}(1 / 0.25)$. As for the chemical environment of Ag atoms contained in the top surface layers, they have both $\mathrm{Ag}-\mathrm{Ag}$ and $\mathrm{Ag}-\mathrm{Au}$ bonds likewise those contained in the samples of Ag/Au powder and the NPG. 


\section{Discussion}

\subsection{Chemical environment of Ag and the catalytic activity for CO oxidation of three kinds of Au-Ag}

bimetallic catalysts

The three kinds of AuAg bimetallic catalysts, i.e., the $\mathrm{Ag} / \mathrm{Au}$ powder, the NPG, and $\mathrm{AuAg} / \mathrm{Al}_{2} \mathrm{O}_{3}$, largely differ one another in the preparation method and in the morphology. However, the enrichment of $\mathrm{Ag}$ in the surface layer was commonly observed in the three $\mathrm{Au}-\mathrm{Ag}$ bimetallic catalysts $[31,32]$ : the three catalysts have similar structure as composed of Au core and AgAu alloy shell.

The relationship between $k_{\mathrm{CO} 2}$ and the XPS surface atomic concentrations of $\mathrm{Ag}$ seen in Figure 1 with respect to the samples of $\mathrm{Ag} / \mathrm{Au}$-powder except $\mathrm{Ag} / \mathrm{Au}-03$ clearly shows that $\mathrm{Ag}$ atoms enriched in the surface layer take part in the $\mathrm{CO}$ oxidation exhibited by them [23]. From the other point of view, the catalytic activity of $\mathrm{Ag} / \mathrm{Au}$ powder ascribed to the surface proper to gold can be said to be negligible, because the sample of Au-07 having Ag XPS surface concentration of at most 1.1 at \% shows very small activity compared to those of the other four samples of $\mathrm{Ag} / \mathrm{Au}$ powder, i.e., $\mathrm{Ag} / \mathrm{Au}-\mathrm{a}, \mathrm{Ag} / \mathrm{Au}-\mathrm{b}, \mathrm{Ag} / \mathrm{Au}-\mathrm{c}$, and $\mathrm{Ag} / \mathrm{Au}-\mathrm{d}$ as presented in Figure 1[23].

In the Arrhenius plots of $k_{\mathrm{CO} 2}$ shown in Figure 7, Ea of $\mathrm{Ag} / \mathrm{Au}-\mathrm{b}, \mathrm{NPG}, \mathrm{AuAg}(1 / 0.25) / \mathrm{Al}_{2} \mathrm{O}_{3}$, and $\mathrm{AuAg}(1 / 1) / \mathrm{Al}_{2} \mathrm{O}_{3}$ were calculated to be $5.2 \mathrm{~kJ} / \mathrm{mol}, 6.6 \mathrm{~kJ} / \mathrm{mol}, 6.9 \mathrm{~kJ} / \mathrm{mol}$, and $13.3 \mathrm{~kJ} / \mathrm{mol}$, respectively. The values of $E$ a of former three samples are particularly near one another and low. We consider from this fact that 1) the $\mathrm{CO}$ oxidation on three bimetallic catalysts proceeds according to a similar mechanism on active sites having similar structure and 2) Ag atoms enriched and dispersed near to the top surface layer of the three Au-Ag bimetallic catalysts produce new catalytically active sites for the $\mathrm{CO}$ oxidation with surrounding $\mathrm{Au}$ atoms irrespective their method of preparation and morphology. In fact, the results of EXAFS analysis of the three AuAg bimetallic catalysts indicate that $\mathrm{Ag}$ atoms are in a similar chemical environment: $\mathrm{Ag}$ atoms are surrounded by $\mathrm{Ag}-\mathrm{Ag}$ and $\mathrm{Ag}-\mathrm{Au}$ bonds (Tables 4, 6 and 7). However, the values of $k_{\mathrm{CO} 2}$ of each sample of AgAu bimetallic catalysts differ from one sample to another as seen in Figures 1 and 7 . This may reflect differences among the AuAg bimetallic catalysts in 1) the CNs of Ag-Ag and Ag-Au around Ag atoms (Tables 4, 6, and 7) and 2) the amount and the extent of the surface enrichment of Ag (Table 3).

Let us examine the catalytic activity for $\mathrm{CO}$ oxidation of respective $\mathrm{Au}-\mathrm{Ag}$ bimetallic catalysts in connection with their chemical environments of $\mathrm{Ag}$. As seen in Figure 1, the value of $\mathrm{Ag} / \mathrm{Au}-\mathrm{c}$ shows slight upward deviation from this relationship. With respect to $\mathrm{Ag} / \mathrm{Au}-\mathrm{c}$, most of $\mathrm{Ag}$ atoms are expected to exist on top two surface layers from the results presented in Table 3. In this case, EXAFS analysis can bring most reliable information about the local structure around active sites. Comparing with the model structure illustrated in Figure 4 which shows Ag-Ag bonds exposed on the top surface, the results of EXAFS analysis of Ag/Au-c in Table 4 seem to show that the $\mathrm{Ag}$ atoms exist within top two surface layers with maintaining Ag-Ag bonds and having unsaturated coordinate bonds. As for the samples of Ag/Au-a Ag/Au-b and Ag/Au-d, they have similar chemical environment of $\mathrm{Ag}$ as that of $\mathrm{Ag} / \mathrm{Au}-\mathrm{c}$ as seen in Table 4. However, their extents of the surface enrichment of $\mathrm{Ag}$ are smaller than that of $\mathrm{Ag} / \mathrm{Au}-\mathrm{c}$ as shown in Table 3. Therefore, these samples may exhibit the somewhat smaller catalytic activities for $\mathrm{CO}$ oxidation than that of $\mathrm{Ag} / \mathrm{Au}-\mathrm{c}$.

In the case of $\mathrm{Ag} / \mathrm{Au}-03$, the extent of surface enrichment of $\mathrm{Ag}$ is the lowest among the five samples of $\mathrm{Ag} / \mathrm{Au}$ powder (Table 3). Furthermore, the result of EXAFS analysis shows that the ratio of $C N$ of Ag-Au to Ag-Ag is smaller than the other 4 samples (Table 4), indicating that the extent of the dispersion of $\mathrm{Ag}$ atoms in the surface layers and the bulk of $\mathrm{Ag} / \mathrm{Au}-03$ is worse than those of the other 4 samples of $\mathrm{Ag} / \mathrm{Au}$ powder. These two factors may cause the exceptionally poor activity for $\mathrm{CO}$ oxidation of the sample of $\mathrm{Ag} / \mathrm{Au}-03$ seen in Figure 1. Judging from this result together with 
those of NPG and $\mathrm{AuAg}(1 / 1) / \mathrm{Al}_{2} \mathrm{O}_{3}$ described later, it seems that $\mathrm{Ag}$ atoms have to be dispersed at least to the level presented in the model in Figure 4 in order to work highly active sites for the catalysis of the $\mathrm{CO}$ oxidation. The results reported by Déronzier et al. that the catalytic activities normalized by the specific area of the NP Ag/Au catalysts for the CO oxidation are in the order $\mathrm{Ag}_{2} \mathrm{Au}_{98}>\mathrm{Ag}_{4} \mathrm{Au}_{96}>\mathrm{Ag}_{6} \mathrm{Au}_{94}$ are interesting in this connection [32].

In Figure 5 which depicts the process of the formation of the NPG by selective etching of Ag from the $\mathrm{Ag} / \mathrm{Au}$ alloy, the current almost ceased near at $30 \mathrm{~min}$ after starting the anode etching. Since the weight loss of the AuAg alloy agreed well with the amount of Ag calculated from the current integrated for $90 \mathrm{~min}$, a large part of Ag contained in AuAg alloy and easily dissolved into nitric acid during first 30 min must be metallic in nature. $\mathrm{D}$. Li et al. performed recently the $\mathrm{CO}$ oxidation by using dealloyed NPG catalysts with different Ag contents, i.e., 50.2, 5.3, and 0.99 at. \% and reported that the catalytic activity of NPG was remarkably improved as the Ag content decreased [20]. Probably Ag having metallic nature in NPG retarded the catalytic oxidation of CO.

The NPG used in this work was obtained by performing the etching for $90 \mathrm{~min}$. The amount of Ag remained in NPG was $1.5 \mathrm{wt} \%$. The amount could hardly be decreased by prolonging the etching time for further $60 \mathrm{~min}$. In other words, the residual Ag in NPG after etching for $90 \mathrm{~min}$ is hard to be oxidized to $\mathrm{Ag}^{+}$to be dissolved into concentrated nitric acid even under applied potential. The chemical environment of the residual Ag presented in Table 5(b) and Table 6 shows that the residual $\mathrm{Ag}$ atoms are dispersed in the top surface layers of NPG by forming $\mathrm{Ag}-\mathrm{Ag}$ and $\mathrm{Ag}-\mathrm{Au}$ bonds. The number of Ag-Au bond is larger than that of Ag-Ag bond. This chemical environment must give the chemical nature of residual Ag atoms hard to be dissolved into nitric acid.

Figures 1 and 7 show the activity of active sites containing the residual Ag atoms for the catalytic oxidation of $\mathrm{CO}$. The plot of $k_{\mathrm{CO} 2}$ in Figure 1 deviates downward from the linear line connecting $\mathrm{Ag} / \mathrm{Au}-\mathrm{a}, \mathrm{Ag} / \mathrm{Au}-\mathrm{b}$, and $\mathrm{Ag} / \mathrm{Au}-\mathrm{d}$ of which ratios of $\mathrm{CN}$ of $\mathrm{Ag}-\mathrm{Au}$ to that of $\mathrm{Ag}-\mathrm{Ag}$ are larger than 3. On the other hand, the ratio of CN of Ag-Au to that of Ag-Ag in the NPG is smaller than 3 as can be seen in Table 6. The chemical environment of Ag atoms contained in the NPG seems to be near to that of $\mathrm{Ag} / \mathrm{Au}-03$ and may explain somewhat small activity shown in Figure 1 as well as somewhat larger Ea seen in Figure 7.

The content of Ag in both colloidal NPs of $\mathrm{AuAg}(1 / 1)$ and $\mathrm{AuAg}(1 / 0.25)$ are far larger than those contained in the other Au-Ag bimetallic catalysts. However, the results of EXAFS analysis at Au $\mathrm{L}_{\mathrm{III}}$ - and Ag K-edges presented in Figure 9, Figure S4, and Table 7 indicate that both AuAg colloidal NPs have an Au core and AuAg alloy shell structure likewise the Ag/Au powder and NPG catalysts. The results of calculation presented in Table 8 on mean $C N$ s around Ag atoms based on their model structure support the Au core and AuAg alloy shell structure indicated by their EXAFS analysis and suggest that Ag atoms enriched in top two surface layers of both colloidal NPs exist in similar chemical environment to those in the other $\mathrm{Au}-\mathrm{Ag}$ bimetallic catalysts. Reflecting the difference in the content of Ag, Ag atoms in the model of the AuAg (1/1) NPs with the atomic ratio of $\mathrm{Au} / \mathrm{Ag}=1 / 0.5$ exist in top two surface layers composed of $\mathrm{Au}$ and $\mathrm{Ag}$ with a ratio of $\mathrm{Ag}: \mathrm{Au}=5: 4$, whereas those in the model of the AuAg (1/0.25) NPs with the atomic ratio of $\mathrm{Au} / \mathrm{Ag}=1 / 0.2$ exist in top two surface layers with a ratio of about $\mathrm{Ag}: \mathrm{Au}=2: 1$. If we accept these models, the difference in the plots of $k_{\mathrm{CO} 2}$ with respect to $\mathrm{AuAg} / \mathrm{Al}_{2} \mathrm{O}_{3}(1 / 1)$ and $\mathrm{AuAg} / \mathrm{Al}_{2} \mathrm{O}_{3}(1 / 0.25)$ presented in Figure 7 can be understood in the similar manner as $\mathrm{Ag} / \mathrm{Au}$ powder and NPG. The higher activities shown by $\mathrm{AuAg} / \mathrm{Al}_{2} \mathrm{O}_{3}(1 / 0.25)$ compared to $\mathrm{AuAg} / \mathrm{Al}_{2} \mathrm{O}_{3}(1 / 1)$ would be due to the higher extent of the dispersion of $\mathrm{Ag}$ atoms in the top two surface layers in the former sample than that in the latter one. Since $\mathrm{AgAu} / \mathrm{Al}_{2} \mathrm{O}_{3}(1 / 1)$ shows the value of $E_{\mathrm{a}}$ larger than that of $\mathrm{AuAg} / \mathrm{Al}_{2} \mathrm{O}_{3}(1 / 0.25), \mathrm{Ag}$ atoms with low dispersion may work against the catalytic oxidation of $\mathrm{CO}$ in active sites.

It is worth to mention that Wang et al. reported that 1) the activity of Ag-Au alloy catalysts supported on mesoporous alumino silicate changed dramatically with the variation with $\mathrm{Au} / \mathrm{Ag}$ ratios, 2) the activity with a $\mathrm{Au} / \mathrm{Ag}$ ratio of 3:1 has the highest activity, and 3) the activity decreased when the $\mathrm{Au} / \mathrm{Ag}$ ratio was decreased from 3:1 to 1:1 [13]. 


\subsection{Chemical environment of $\mathrm{Ag}$ and the mechanism of the catalytic oxidation of $\mathrm{CO}$ with $\mathrm{O}_{2}$ on}

Au-Ag bimetallic catalysts

Wang et al. proposed the mechanism of $\mathrm{CO}$ oxidation with $\mathrm{O}_{2}$ on $\mathrm{AuAg}$ colloid prepared in meso-porous aluminosilicate, and explained the reason for the high catalytic activity by the coadsorption of $\mathrm{CO}$ and $\mathrm{O}_{2}$ taking place on such active sites as composed of $\mathrm{Au}$ and neighboring $\mathrm{Ag}$ atoms [13]. Chang and his coworkers performed the theoretical investigation on the $\mathrm{CO}$ oxidation on unsupported icosahedral nanocluster of $\mathrm{Au}_{25} \mathrm{Ag}_{30}$, which consists of $\mathrm{Au}_{13}$ core and $\mathrm{Au}_{12} \mathrm{Ag}_{30}$ shell [38]. The shell is composed of $20 \mathrm{Au}_{3} \mathrm{Ag}_{3}$ triangles, in each of which $3 \mathrm{Au}$ and $3 \mathrm{Ag}$ atoms occupy 3 vertex sites and 3 edge sites between 2 vertex Au atoms, respectively [38]. The proposed reaction path involves OOCO transition intermediate which forms through the coadsorption of $\mathrm{CO}$ adsorbed on $\mathrm{Au}$ vertex site and $\mathrm{O}_{2}$ adsorbed on the bridge site connecting two edge Ag atoms: the OOCO complex decomposes to produce a $\mathrm{CO}_{2}$ molecule leaving one oxygen atom on the cluster: the oxygen atom remained then reacts with $\mathrm{CO}$ to produce another $\mathrm{CO}_{2}$ molecule with low activation barrier [38]. The reaction mechanism of $\mathrm{CO}$ oxidation with $\mathrm{O}_{2}$ investigated on $\mathrm{Ag} / \mathrm{Au}-\mathrm{b}$ on the basis of the kinetic measurements has been described in the Introduction section of the present work [24]. It is noteworthy that the reaction mechanism elucidated on Ag/Au-b based on experimental evidence [24] agrees perfectly with that deduced from the theoretical investigation [38].

Furthermore, the chemical environment of Ag illustrated in Figure 4 which represents Ag atoms exposed on the top surface layer of three kinds of Au-Ag bimetallic catalysts basically agrees with that proposed on the $\mathrm{Au}_{25} \mathrm{Ag}_{30}$ cluster [38]: $\mathrm{Ag}$ atoms exposed on the top surface of the $\mathrm{Au}_{25} \mathrm{Ag}_{30}$ cluster have both $\mathrm{Ag}-\mathrm{Au}$ and $\mathrm{Ag}-\mathrm{Ag}$ bonds in the $\mathrm{AuAg}$ alloy shell which covers subsurface $\mathrm{Au}_{13}$ core. This feature of the chemical environment of Ag, in other words, AgAu alloy shell over $\mathrm{Au}$ core, is common to $\mathrm{Ag}$ atoms in three kinds of AuAg bimetallic catalysts.

The authors consider that this feature of the chemical environment of Ag atoms must be essential for generating the catalytic activity of AuAg bimetallic catalysts for the oxidation of $\mathrm{CO}$ with $\mathrm{O}_{2}$. Zhang et al. proposed that the formation of Au-Ag bond induces the charge transfer from $\mathrm{Ag}$ to $\mathrm{Au}$ and ascribed the higher activity of the Ag/Au NPs for the glucose oxidation to the negatively charged $\mathrm{Au}$ atoms [15]. Chang et al. described that when the co-adsorption of $\mathrm{CO}$ molecule on the vertex $\mathrm{Au}$ site and $\mathrm{O}_{2}$ molecule on the bridge site connecting two edge Ag atoms occurs on $\mathrm{Au}_{25} \mathrm{Ag}_{30}$ alloy clusters, the co-adsorption energy on the $\mathrm{Au}_{25} \mathrm{Ag}_{30}$ alloy cluster is larger than those calculated on the monometallic $\mathrm{Au}_{55}$ and $\mathrm{Ag}_{55}$ clusters. This suggests that both $\mathrm{CO}$ and $\mathrm{O}_{2}$ can be more easily coadsorbed on such sites containing Au-Ag bond in the Au-Ag alloy and the co-adsorption should lead to a higher reactivity for CO oxidation. Since 1) Ag-Ag bonds could be detected for all the three kinds of AuAg bimetallic catalysts and 2) the higher values of $k_{\mathrm{CO} 2}$ were observed on AuAg bimetallic catalysts which have higher extent of the dispersion of Ag, the charge transfer from Ag-Ag paired sites to surrounding Au atoms seems to be critical for generating the active sites having high catalytic activity for the oxidation of $\mathrm{CO}$ with $\mathrm{O}_{2}$.

In closing the Discussion section, it is significant to describe about the activation of $\mathrm{O}_{2}$ molecules on Ag sites, because the discussion seems to be generally accepted among almost investigators in the field of the oxidation on AuAg bimetallic catalysts [11-17, 24, 32, 35]. In this case, to investigate the existence of oxygen atoms around Ag atoms by means of the Ag K edge EXAFS measurement may give the valuable information about the process of the activation of oxygen. Yen et al. have included the Ag-O bond in the curve fitting results of the EXAFS data at Ag K edge of the AuAg@APTS-MCM with Au/Ag ratios of 8/1 and 4/1 taken after calcinations in air at $833 \mathrm{~K}$ for $6 \mathrm{hr}$ [14].

The Fourier transform of $k^{3}$-weighted EXAFS oscillation extracted from Ag K-edge XAS of $\mathrm{Ag} / \mathrm{Au}-\mathrm{b}$ in Figure 3 was taken after the pretreatment in circulating oxygen of $1 \mathrm{~atm}$ at $453 \mathrm{~K}$ for 1 $\mathrm{hr}$, because the sample showed the maximum activity after the treatment [23, 24].

Since a distinct peak can be observed at $R$ less than $2 \AA$, the curve fitting analysis was performed 
whether the peak could be attributable to the Ag-O bond or not. However, the curve fitting analysis of the peak did not give reasonable structural parameters at all. The Fourier transform of

$k^{3}$-weighted EXAFS oscillation extracted from XAS of $\mathrm{Ag}_{2} \mathrm{O}$ taken as reference is shown in Figure 3 , which show the peak due to Ag-O at $R$ near $1.6 \AA$. It is worth to note that the peak from $\mathrm{Ag} / \mathrm{Au}-\mathrm{b}$ is positioned at $R$ much less than that of Ag-O.

The bond distance presented in Table 4 clearly show that $\mathrm{Ag}$ atoms contained in $\mathrm{Ag} / \mathrm{Au}$ powder including $\mathrm{Ag} / \mathrm{Au}-\mathrm{b}$ form metallic bond with surrounding several $\mathrm{Ag}$ and $\mathrm{Au}$ atoms. In this case, the authors think that they are hard to be oxidized by $\mathrm{O}_{2}$ to form $\mathrm{Ag}-\mathrm{O}$ at least near room temperature even they exist on the topmost surface layers. The formation of Ag-O bond needs to break a few metallic bonds. We can see the difficulty from the fact that $\mathrm{Ag}$ atoms remained in the surface layer of NPG are hard to be dissolved into concentrated nitric acid even under applied potential (see Figure 5). The activation of $\mathrm{O}_{2}$ molecule on active site typically depicted in Figure 4 would occur through the coadsorption between $\mathrm{O}_{2}$ loosely adsorbed on $\mathrm{Ag}-\mathrm{Ag}$ paired sites and $\mathrm{CO}$ adsorbed on neighboring Au site as described in [24] and [38].

\section{Conclusion}

The chemical environment of the five samples of $\mathrm{Ag}$ contaminated $\mathrm{Au}$ powder (Ag/Au-a, $\mathrm{Ag} / \mathrm{Au}-\mathrm{b}$, $\mathrm{Ag} / \mathrm{Au}-\mathrm{c}, \mathrm{Ag} / \mathrm{Au}-\mathrm{d}$, and $\mathrm{Ag} / \mathrm{Au}-03$ ), of which catalytic activities for $\mathrm{CO}$ oxidation had previously been shown to be almost proportional to the XPS surface concentrations of Ag, were examined by evaluating their extents of the surface enrichment of $\mathrm{Ag}$ and by Ag K-edge EXAFS analysis to get insight into the nature of active sites for $\mathrm{CO}$ oxidation. As for $\mathrm{Ag} / \mathrm{Au}-\mathrm{c}$ with $\mathrm{Ag}$ content of 0.038 $\mathrm{wt} \%$, almost all the Ag atoms were suggested to exist within top two surface layers and work as active sites for CO oxidation. The Ag K-Edge EXAFS analysis revealed that the trace amounts of $\mathrm{Ag}$ are dispersed atomically by forming $\mathrm{Ag}-\mathrm{Au}$ bonds and by maintaining the Ag-Ag bond slightly. In the case of $\mathrm{Ag} / \mathrm{Au}-03$, which contains ca. 7 times larger $\mathrm{Ag}$ atoms than that of $\mathrm{Ag} / \mathrm{Au}-\mathrm{c}$, and shows exceptionally poor activity for $\mathrm{CO}$ oxidation, a large part of Ag was suggested to exist in the bulk and not to contribute to the oxidation of $\mathrm{CO}$. Furthermore, the extent of the dispersion of $\mathrm{Ag}$ atoms in the surface layers of $\mathrm{Ag} / \mathrm{Au}-03$ was suggested to be worse than those of the other 4 samples of $\mathrm{Ag} / \mathrm{Au}$ powder from the ratio of $\mathrm{CN}$ of $\mathrm{Ag}-\mathrm{Au}$ to $\mathrm{Ag}-\mathrm{Ag}$.

The nanoporous gold (NPG) and the AgAu bimetallic alloy colloids (AgAu) were prepared to compare their catalytic activity for $\mathrm{CO}$ oxidation as well as the chemical circumstances of Ag with those investigated on the Ag/Au powder. The amounts of Ag left in NPG was only $1.5 \mathrm{wt} \%$, but many of them are suggested to exist within top two surface layer likewise in the case of $\mathrm{Ag} / \mathrm{Au}$ powder. The results of the EXAFS analysis suggest that the chemical environment of Ag contained in the NPG seems to be near to that of $\mathrm{Ag} / \mathrm{Au}-03$ rather than that of $\mathrm{Ag} / \mathrm{Au}-\mathrm{c}$. Two samples of $\mathrm{AuAg}$ bimetallic colloidal NPs, i.e., $\mathrm{AuAg}(1 / 1)$ and $\mathrm{AuAg}(1 / 0.25)$ contain far large amount of $\mathrm{Ag}$ compared to five samples of Ag/Au powder and the NPG. The EXAFS analysis at Ag K- and at Au $\mathrm{L}_{\mathrm{III}}$ - edges performed on both samples indicated that Ag dissolved into the surface layer of the colloidal NPs of Au to form the AuAg alloy shell which covers the Au core NPs likewise in the 5 samples of $\mathrm{Ag} / \mathrm{Au}$ powder and NPG.

The Arrhenius plots of the value of $k_{\mathrm{CO} 2}$ of three kinds bimetallic catalysts without $\mathrm{AuAg} / \mathrm{Al}_{2} \mathrm{O}_{3}(1 / 1)$ showed almost the same slope: the $\mathrm{CO}$ oxidation on three bimetallic catalysts proceed according to the similar mechanism on active sites with similar chemical structure. The formation of Ag-Au bonds in the AgAu alloy shell maintaining Ag-Ag bond over Au core may be essential for generating the catalytic activity of AuAg bimetallic catalysts for the oxidation of CO.

\section{Acknowledgement}

The synchrotron radiation experiments were performed at the BL14B2 of SPring- 8 with the 
approval of the Japan Synchrotron Radiation Research Institute (JASRI) (Proposal No. 2011B1001, 2011A1003, 2010B1006, 2010A1001, 2009B1007, 2009A1018, 2008B1003, 2008A1003).

This research was supported by JST, CREST project (Catalyst Design of Gold Clusters through Junction Effect with Metal oxides, Carbons, and Polymers)

\section{References}

[1] M. Haruta, T. Kobayashi, H. Sano, N. Yamada, Chem. Lett. (1987)405-408.

[2] M. Haruta, N. Yamada, T. Kobayashi, S. Iijima, J. Catal. 115(1989)301-309.

[3] G. C. Bond, D. T. Thompson, Catal. Rev.-Sci. Eng. 41(1999)319-388.

[4] G. C. Bond, C. Louis, D. T. Thompson : G. J. Hutchings (Ed.), Catalysis by Gold, in: Catalytic Science Series, vol. 6, Imperial College Press, London, 2006.

[5] H. Zhang, T. Watanabe, M. Okumura, M. Haruta, N. Toshima, Nature Mater. 11(2012) 49-52.

[6] R. N. Dhital, C. Kamonsatikul, E. Somsook, K. Bobuatong, M. Ehara, S. Karanjit, H. Sakurai, J. Ame. Chem. Soc. 134 (2012) 20250-20253.

[7] G. J. Hutchings, Chem. Commun. (2008) 1148-1164.

[8] L. Teevs, K.-D. Vorlop, U. Prüße, Catal. Commun. 14 (2011) 96-100.

[9] C. D. Pina, E. Falletta, M. Rossi, J. Catal. 260(2008)384-386.

[10] F. Cárdenas-Lizana, S. Gómez-Quero, G. Jacobs, Y. Ji, B. H. Davis, L. Kiwi-Minsker, M. A. Keane, J. Phys. Chem. C,116 (2012) 11166-11180.

[11] J. H. Liu, A. Q. Wang, Y. S. Chi, H. P. Lin, C. Y. Mou, J. Phys. Chem. B 109(2005)40-43.

[12] A. Q. Wang, C. M. Chang, C. Y. Mou, J. Phys. Chem. B 109(2005)18860-18867.

[13] A. Q. Wang, J. H. Liu, S. D. Lin, T. S. Lin, C. Y. Mou, J. Catal. 233(2005)186-197.

[14] C. W. Yen, M. L. Lin, A. Wang, S. A. Chen, J. M. Chen, C. Y. Mou, J. Phys. Chem. C 113(2009)17831-17839.

[15] H. Zhang, J. Okuni, N. Toshima, J. Coll. Interf. Sci. 354(2011)131-138.

[16] A. Wittstock, V. Zielasek, J. Biener, C. M. Friend, M. Bäumer, Science 327(2010)319-322.

[17] V. Zielasek, B. Jürgens, C. Schulz, J. Biener, M. M. Biener, A. V. Hamza, M. Bäumer, Angew. Chem. Int. Ed. 45 (2006)8241-8244.

[18] C. Xu, J. Su, X. Xu, P. Liu, H. Zhao, F. Tian, Y. Ding, J. Am. Chem. Soc. 129(2007)42-43.

[19] C. Xu, X. Xu, J. Su, Y. Ding, J. Catal. 252(2007)243-248.

[20] D. Li, Y. Zhu, H. Wang, Y. Ding, Sci. Rep. 3 (2013) 3015.

[21] H. Yin, C. Zhou, C. Xu, P. Liu, X. Xu, Y. Ding, J. Phys. Chem. C 112(2008)9673-9678.

[22] T. Fujita, P. Guan, K. McKenna, X. Lang, A. Hirata, L. Zhang, T. Tokunaga, S. Arai, Y. Yamamoto, N. Tanaka, Y. Ishikawa, N. Asao, Y. Yamamoto, J. Erlebacher, M. Chen, Nature Mater. 11(2012)775-780.

[23] Y. Iizuka, A. Kawamoto, K. Akita, M. Daté, S. Tsubota, M. Okumura, M. Haruta, Catal. Lett. 97 (2004) 203-208.

[24] Y. Iizuka, T. Miyamae, T. Miura, M. Okumura, M. Daté, M. Haruta, J. Catal. 262 (2009) 280-286.

[25] S. Tokonami, N. Morita, K. Takasaki, N. Toshima, J. Phys. Chem. C 114(2010)10336-10341.

[26] Y. Iizuka, T.Miura, N. Toshima, N. Morita, T. Akita, GOLD2009, THE $5^{\text {th }}$ INTERNATIONAL CONFERENCE ON GOLD SCIENCE, TECHNOLOGY AND ITS APPLICATIONS, University of Heidelberg, Germany, 26-29 July 2009, p.261.

[27] T. Honma, H. Oji, S. Hirayama, Y. Taniguchi, H. Ofuchi, and M. Takagaki, AIP Conf. Proc., 1234 (2010) 13-16.

[28] H. Oji, Y. Taniguchi, S. Hirayama, H. Ofuchi, M. Takagaki, and H. Honma, J. Synchrotron Rad., 19 (2012) 54-59.

[29] B. Ravel, M. Newville, J. Synchrotron Rad. 12(2005)537-541.

[30] A. Jablonski, C. J. Powell, J. Vac. Sci. Technol. A 21(2003)274-283

[31] K. Kim, K. L. Kim, J. Y. Choi, H. B. Lee, K. S. Shin, J. Phys. Chem., C 114(2010)3448-3453. 
[32] T. Déronzier, F. Morfin, M. Lomello, J. L. Rousset, J. Catal. 311(2014)221-229.

[33] M. Haruta, S. Tsubota, T. Kobayashi, H. Kageyama, M. J. Genet, B. Delmon, J. Catal. 144(1993)175-192.

[34] M. Haruta, Faraday Discuss. 152(2011) 11-32

[35] H. Zhang, M. Haba, M. Okumura, t. Akita, S. Hahimoto, N. Toshima, Langmuir 29(2013)10330-10339.

[36] N. Toshima, M. Harada, T. Yonezawa, K. Kushihashi, K. Asakura, J. Phys. Chem. 95(1991)7448-7453.

[37] M. Harada, K. Asakura, N. Toshima, J. Phys. Chem. 98(1994)2653-2662.

[38] C. M. Chang, C. Cheng, and C. M. Wei, J. Chem. Phys. 128 (2008) 124710-124714 


\section{Table Captions}

Table 1 BET surface area, ICP bulk and XPS surface compositions of Ag/ Au powder excerpted from [23]

Table 2 Structural parameters obtained by the curve fitting analysis of Ag K-edge EXAFS of three kinds of molten AgAu plates with different molar compositions

Table 3 Estimation of the extent of the surface enrichment of Ag on five samples of $\mathrm{Ag} / \mathrm{Au}$ powders

Table 4 Structural parameters obtained by the curve fitting analysis of Ag K-edge EXAFS of Au-a, Au-b, Au-c, Au-d, and Au-03

Table 5 (a) Comparison of the Ag weight obtained by three different methods (b) BET surface area, ICP bulk content and XPS surface composition of Ag determined on NPG prepared

Table 6 Structural parameters obtained by the curve fitting analysis of Ag K-edge EXAFS of the NPG

Table 7 Structural parameters obtained by the curve fitting analysis of (a) Au $\mathrm{L}_{\text {III }}$-edge and (b) Ag K-edge EXAFS of PVP/AuAg=1/1 and PVP/AuAg=1/0.25.

Table 8 Comparison of $\mathrm{CN}$ around $\mathrm{Au}$ and $\mathrm{Ag}$ atoms of PVP protected $\mathrm{AuAg}$ colloidal particles between those observed and those calculated based on their model structure 
Table 1 BET surface area, ICP bulk and XPS surface compositions of Ag/ Au powder excerpted from [23]

\begin{tabular}{|c|c|c|c|c|c|c|c|}
\hline \multirow[t]{2}{*}{ Sample } & \multirow{2}{*}{$\begin{array}{c}\text { BET } \\
\text { surfac } \\
\text { e area } \\
/ \mathrm{m}^{2} \mathrm{~g}^{-1}\end{array}$} & \multicolumn{3}{|c|}{$\begin{array}{c}\text { ICP bulk } \\
\text { composition/wt } \%^{\text {a }}\end{array}$} & \multicolumn{3}{|c|}{$\begin{array}{c}\text { XPS surface } \\
\text { composition/atomic\% }\end{array}$} \\
\hline & & $\mathrm{Au}$ & $\mathrm{Ag}$ & $\begin{array}{c}\text { Sum of } \\
\text { the } \\
\text { others }\end{array}$ & $\mathrm{Au}$ & $\mathrm{Ag}$ & In \\
\hline $\mathrm{Ag} / \mathrm{Au}-\mathrm{a}$ & 14.9 & 88.5 & 10.4 & 1.1 & 57.0 & 40.9 & 2.1 \\
\hline $\mathrm{Ag} / \mathrm{Au}-\mathrm{b}$ & 2.67 & 99.8 & 0.11 & 0.08 & 89.2 & 10.8 & 0.0 \\
\hline $\mathrm{Ag} / \mathrm{Au}-\mathrm{c}$ & 3.03 & 99.5 & 0.038 & 0.45 & 78.4 & 4.9 & 16.7 \\
\hline $\mathrm{Ag} / \mathrm{Au}-\mathrm{d}$ & 1.31 & 99.5 & 0.05 & 0.45 & 92.8 & 4.0 & 3.3 \\
\hline $\mathrm{Ag} / \mathrm{Au}-03$ & 1.51 & 99.7 & 0.28 & 0.02 & 93.5 & 6.5 & 0.0 \\
\hline
\end{tabular}

a The details of the results of ICP analysis were described in Table 1 in [23]. $\mathrm{b}$ The effect of In on the activity of $\mathrm{Ag} / \mathrm{Au}$ powder was discussed and described in [23]. 
Table 2 Structural parameters obtained by the curve fitting analysis of Ag K-edge EXAFS of three kinds of molten AgAu plates with different molar compositions

\begin{tabular}{llccccc}
\hline sample & bond & $C N^{\mathrm{a}}$ & $R / \AA^{\mathrm{b}}$ & $\Delta E / \mathrm{eV}^{\mathrm{c}}$ & $\sigma^{2} / \AA^{2 \mathrm{~d}}$ & $\begin{array}{l}R \text {-factor } \\
1 \%{ }^{\mathrm{e}}\end{array}$ \\
\hline $\mathrm{Ag}_{90} \mathrm{Au}_{10}$ & $\mathrm{Ag}-\mathrm{Ag}$ & 7.8 & 2.86 & 2.7 & 0.0098 & 0.28 \\
& $\mathrm{Ag}-\mathrm{Au}$ & 1.6 & 2.86 & 2.7 & 0.0119 & \\
$\mathrm{Ag}_{50} \mathrm{Au}_{50}$ & $\mathrm{Ag}-\mathrm{Ag}$ & 4.9 & 2.85 & 1.06 & 0.0173 & 0.34 \\
& $\mathrm{Ag}-\mathrm{Au}$ & 4.9 & 2.85 & 1.06 & 0.0073 & \\
$\mathrm{Ag}_{10} \mathrm{Au}_{90}$ & $\mathrm{Ag}-\mathrm{Ag}$ & 0.88 & 2.78 & 0.69 & 0.0059 & 0.11 \\
& $\mathrm{Ag}-\mathrm{Au}$ & 9.7 & 2.86 & 0.69 & 0.0076 & \\
\hline
\end{tabular}

${ }^{\mathrm{a}} C N$ : coordination number; ${ }^{\mathrm{b}} R / \AA \dot{\text { : }}$ bond length; ${ }^{\mathrm{c}} \Delta E / \mathrm{eV}$ : edge shift;

${ }^{\mathrm{d}} \sigma^{2} / \AA^{2}$ :Debye Waller factor; ${ }^{\mathrm{e}} R$-factor/\%: the goodness-of-fit index. 
Table 3 Estimation of the extent of the surface enrichment of $\mathrm{Ag}$ on five samples of $\mathrm{Ag} / \mathrm{Au}$ powders

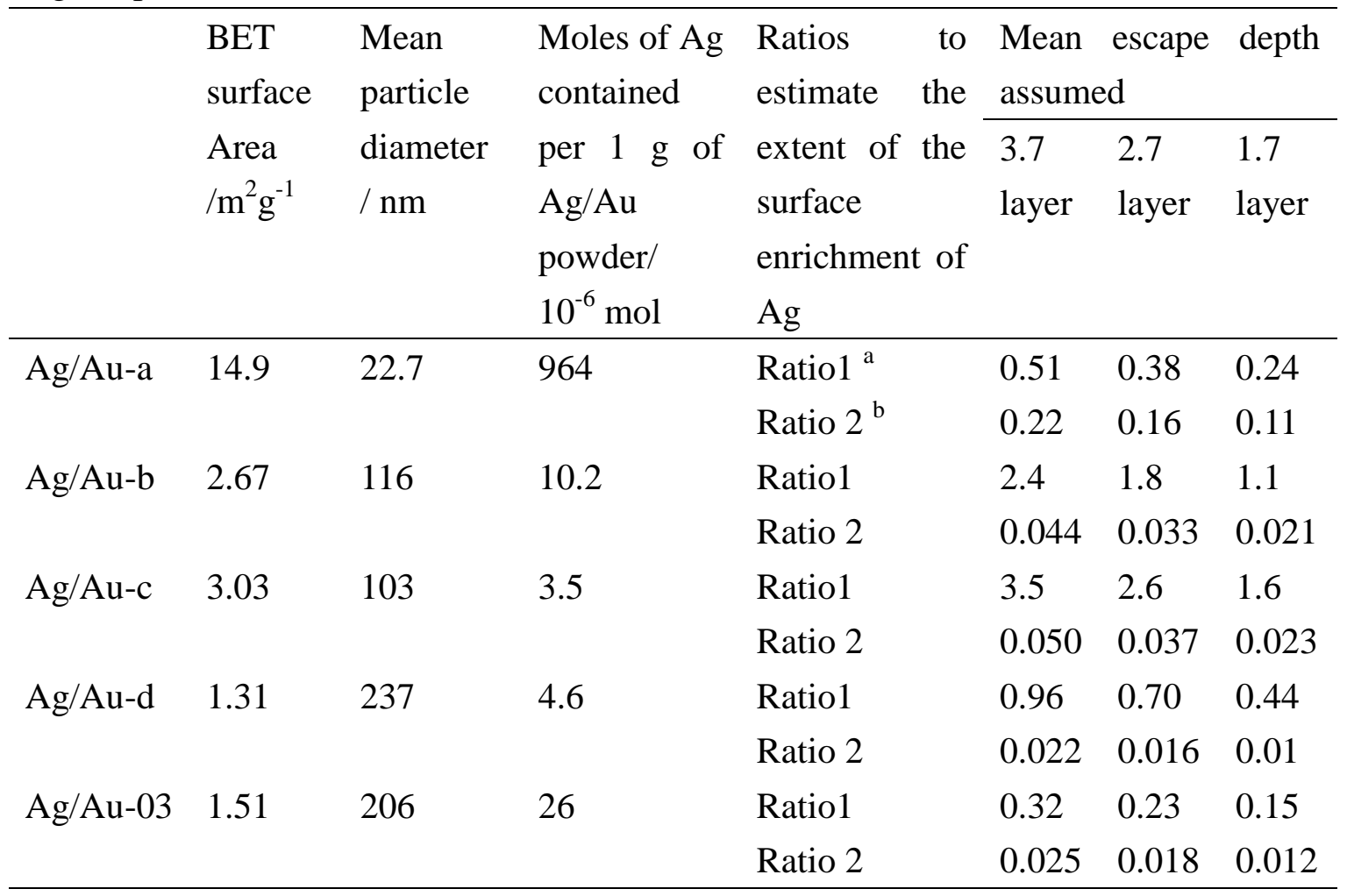

${ }^{a}$ Ratio of the mole number of Ag contained in the surface layer to that contained in the whole sample. The former amount was calculated from BET surface area and the XPS surface atomic concentration of Ag assuming that XPS data gives atomic \% of 3.7, 2.7 and 1.7 surface layers of $\mathrm{Ag} / \mathrm{Au}$ powder.

${ }^{\mathrm{b}}$ Ratio of the mole number of $\mathrm{Au}$ and $\mathrm{Ag}$ atoms contained in the 3.7, 2.7 and 1.7 surface layer assumed to those contained in the whole particle. 
Table 4 Structural parameters obtained by the curve fitting analysis of Ag K-edge EXAFS of Au-a, Au-b, Au-c, Au-d, and Au-03

\begin{tabular}{|c|c|c|c|c|c|c|}
\hline Sample & bond & $C N$ & $R / \AA ́$ & $\Delta E / \mathrm{eV}$ & $\sigma^{2} / \AA^{2}$ & $\begin{array}{c}R \text {-factor } \\
1 \%\end{array}$ \\
\hline \multirow[t]{2}{*}{$\mathrm{Ag} / \mathrm{Au}-\mathrm{a}$} & Ag-Ag & 2.3 & 2.86 & -0.36 & 0.0049 & 0.81 \\
\hline & $\mathrm{Ag}-\mathrm{Au}$ & 9.2 & 2.86 & -0.36 & 0.0117 & \\
\hline \multirow[t]{2}{*}{$\mathrm{Ag} / \mathrm{Au}-\mathrm{b}$} & $\mathrm{Ag}-\mathrm{Ag}$ & 2.1 & 2.86 & 1.63 & 0.0033 & 1.9 \\
\hline & $\mathrm{Ag}-\mathrm{Au}$ & 6.3 & 2.89 & 1.63 & 0.0042 & \\
\hline \multirow[t]{2}{*}{$\mathrm{Ag} / \mathrm{Au}-\mathrm{c}$} & $\mathrm{Ag}-\mathrm{Ag}$ & 2.1 & 2.88 & 0.088 & 0.0114 & 0.23 \\
\hline & $\mathrm{Ag}-\mathrm{Au}$ & 8.9 & 2.85 & 0.088 & 0.0114 & \\
\hline \multirow[t]{2}{*}{$\mathrm{Ag} / \mathrm{Au}-\mathrm{d}$} & $\mathrm{Ag}-\mathrm{Ag}$ & 2.7 & 2.85 & -0.49 & 0.0094 & 0.50 \\
\hline & $\mathrm{Ag}-\mathrm{Au}$ & 9.6 & 2.85 & -1.12 & 0.0091 & \\
\hline \multirow[t]{2}{*}{$\mathrm{Ag} / \mathrm{Au}-03$} & $\mathrm{Ag}-\mathrm{Ag}$ & 2.9 & 2.83 & -0.66 & 0.0059 & 0.53 \\
\hline & $\mathrm{Ag}-\mathrm{Au}$ & 6.8 & 2.85 & -1.07 & 0.0072 & \\
\hline
\end{tabular}

Intrinsic loss factors $S_{0}{ }^{2}$ obtained from $\mathrm{Ag}$ foil data for $\mathrm{Ag} / \mathrm{Au}-\mathrm{a}, \mathrm{Au}-\mathrm{b}, \mathrm{Au}-\mathrm{c}, \mathrm{Au}-\mathrm{d}$, and Au-03 were $0.897,0.890,0.876,0.859,0.890$, respectively. For the definition of the fitting parameters, see those described in the footnote of Table 2. 
Table 5 (a) Comparison of the Ag weight obtained by three different methods Weight calculated from Weight loss of anode Nominal content of Ag in the integrated current by after the etching/g the alloy before the using Faraday's law / g etching / g

$\begin{array}{lll}0.179 & 0.179 & 0.172\end{array}$

(b) BET surface area, ICP bulk content and XPS surface composition of Ag determined on NPG prepared

\begin{tabular}{ccc}
\hline BET surface area $/ \mathrm{m}^{2} \mathrm{~g}^{-1}$ & ICP bulk content $/ \mathrm{wt} \%$ & $\begin{array}{l}\text { XPS } \\
\text { composition } / \%\end{array}$ \\
\hline 62 & 1.5 & 8.6 \\
\hline
\end{tabular}


Table 6 Structural parameters obtained by the curve fitting analysis of Ag K-edge EXAFS of the NPG

\begin{tabular}{lllllll}
\hline Sample & bond & $C N$ & $R / \AA \dot{~}$ & $\Delta E / \mathrm{eV}$ & $\sigma^{2} / \AA^{2}$ & $\begin{array}{l}R \text {-factor } \\
1 \%\end{array}$ \\
\cline { 1 - 6 } NPG & $\mathrm{Ag}-\mathrm{Ag}$ & 2.69 & 2.86 & 1.96 & 0.0046 & \multirow{2}{*}{0.31} \\
\cline { 2 - 6 } & $\mathrm{Ag}-\mathrm{Au}$ & 6.10 & 2.87 & 1.62 & 0.0119 & \\
\hline
\end{tabular}

Intrinsic loss factors $S_{0}{ }^{2}$ obtained from $\mathrm{Ag}$ foil data for this sample was 0.897 . For the definition of the fitting parameters, see those described in the footnote of Table 2. 
Table 7 Structural parameters obtained by the curve fitting analysis of (a) $\mathrm{Au}$ $\mathrm{L}_{\mathrm{III}}$-edge and (b) Ag K-edge EXAFS of PVP/AuAg=1/1 and PVP/AuAg=1/0.25.

(a)

\begin{tabular}{|c|c|c|c|c|c|c|}
\hline Sample & bond & $C N$ & $R / \AA ́$ & $\Delta E / \mathrm{eV}$ & $\sigma^{2} / \AA^{2}$ & $\begin{array}{l}R \text {-factor } \\
1 \%\end{array}$ \\
\hline \multirow{2}{*}{$\begin{array}{l}\text { PVP/AuAg } \\
=1 / 1\end{array}$} & $\mathrm{Au}-\mathrm{Au}$ & 10.3 & 2.85 & 4.29 & 0.0088 & \multirow[t]{2}{*}{0.78} \\
\hline & $\mathrm{Au}-\mathrm{Ag}$ & & & & & \\
\hline \multirow{2}{*}{$\begin{array}{l}\text { PVP/AuAg } \\
=1 / 0.25\end{array}$} & $\mathrm{Au}-\mathrm{Au}$ & 10.5 & 2.85 & 3.95 & 0.0087 & \multirow[t]{2}{*}{0.34} \\
\hline & $\mathrm{Au}-\mathrm{Ag}$ & & & & & \\
\hline
\end{tabular}

Intrinsic loss factor $S_{0}^{2}$ obtained from Au foil data was 0.840 .

(b)

\begin{tabular}{|c|c|c|c|c|c|c|}
\hline Sample & bond & $C N$ & $R / \AA \dot{A}$ & $\Delta E / \mathrm{eV}$ & $\sigma^{2} / \AA^{2}$ & $\begin{array}{l}R \text {-factor } \\
1 \%\end{array}$ \\
\hline \multirow{2}{*}{$\begin{array}{l}\text { PVP/AuAg } \\
=1 / 1\end{array}$} & $\mathrm{Ag}-\mathrm{Ag}$ & 5.0 & 2.90 & 2.90 & 0.013 & \multirow[t]{2}{*}{0.64} \\
\hline & $\mathrm{Ag}-\mathrm{Au}$ & 4.8 & 2.84 & -1.22 & 0.010 & \\
\hline \multirow{2}{*}{$\begin{array}{l}\text { PVP/AuAg } \\
=1 / 0.25\end{array}$} & $\mathrm{Ag}-\mathrm{Ag}$ & 2.5 & 2.82 & -4.03 & 0.0079 & \multirow[t]{2}{*}{1.35} \\
\hline & $\mathrm{Ag}-\mathrm{Au}$ & 4.0 & 2.84 & -7.65 & 0.0082 & \\
\hline
\end{tabular}

Intrinsic loss factor $S_{0}{ }^{2}$ obtained from $\mathrm{Ag}$ foil data $\mathrm{f}$ was 0.853 . For the definition of the fitting parameters, see those described in the footnote of Table 2. 
Table 8 Comparison of $C N$ around $\mathrm{Au}$ and Ag atoms of PVP protected AuAg colloidal particles between those observed and those calculated based on their model structure

\begin{tabular}{|c|c|c|c|c|c|c|c|}
\hline sample & $\mathrm{MD}^{\mathrm{a}}$ & $\begin{array}{l}\text { Ratio } \\
\mathrm{Au} / \mathrm{Ag} \text { b }\end{array}$ & $\begin{array}{l}\text { Absorption } \\
\text { edge }\end{array}$ & bond & $\begin{array}{l}C N \\
\text { Observed } \\
\mathrm{c}\end{array}$ & $\begin{array}{l}\text { Calculat } \\
\text { ed }\end{array}$ & Model \\
\hline \multirow{4}{*}{$\begin{array}{l}\mathrm{PVP} \\
\mathrm{Au} / \mathrm{Ag}=1 / 1\end{array}$} & \multirow[t]{4}{*}{4.2} & \multirow{4}{*}{$\begin{array}{l}\mathrm{Au} / \mathrm{Ag}=1 / 0 . \\
5\end{array}$} & \multirow[t]{2}{*}{$\mathrm{Au} \mathrm{L} \mathrm{L}_{\mathrm{III}}$} & $\mathrm{Au}-\mathrm{Au}$ & 10.1 & 9.0 & \multirow{4}{*}{$\begin{array}{l}\text { Model } \\
\mathrm{A}^{\mathrm{d}}\end{array}$} \\
\hline & & & & $\mathrm{Au}-\mathrm{Ag}$ & nd- & 2.4 & \\
\hline & & & \multirow[t]{2}{*}{$\mathrm{Ag} \mathrm{K}$} & $\mathrm{Ag}-\mathrm{Ag}$ & 5.0 & 5.0 & \\
\hline & & & & $\mathrm{Ag}-\mathrm{Au}$ & 4.8 & 5.3 & \\
\hline \multirow{4}{*}{$\begin{array}{l}\text { PVP } \\
\mathrm{Au} / \mathrm{Ag}=1 / 0 \\
.25\end{array}$} & \multirow[t]{4}{*}{4.6} & \multirow{4}{*}{$\begin{array}{l}\mathrm{Au} / \mathrm{Ag}=1 / 0 \\
2\end{array}$} & \multirow[t]{2}{*}{$\mathrm{Au} \mathrm{L} \mathrm{L}_{\text {III }}$} & $\mathrm{Au}-\mathrm{Au}$ & 10.2 & 9.9 & \multirow{4}{*}{$\begin{array}{l}\text { Model } \\
\mathrm{B}^{\mathrm{e}}\end{array}$} \\
\hline & & & & $\mathrm{Au}-\mathrm{Ag}$ & nd & 1.4 & \\
\hline & & & \multirow[t]{2}{*}{$\mathrm{Ag} \mathrm{K}$} & $\mathrm{Ag}-\mathrm{Ag}$ & 2.5 & 2.8 & \\
\hline & & & & $\mathrm{Ag}-\mathrm{Au}$ & 4.0 & 7.4 & \\
\hline
\end{tabular}

${ }^{\mathrm{a}}$ Mean Diameter based on TEM photograph

${ }^{\mathrm{b}}$ Atomic absorption spectroscopy measurements

${ }^{c}$ Obtained from the curve fitting analyses of EXAFS measurements

${ }^{\mathrm{d}}$ The $1^{\text {st }}$ and $2^{\text {nd }}$ surface layers form an AuAg alloy shell which contains Ag and $\mathrm{Au}$ atoms with a ratio of 5 to 4 . The core under the $3^{\text {rd }}$ surface layer consists of only Au atoms.

e The $1^{\text {st }}$ surface layer and the $2^{\text {nd }}$ surface layers forms an AuAg alloy shell which contains $\mathrm{Ag}$ and $\mathrm{Au}$ atoms with a ratio of 3 to 6 and a ratio of 2.5 to 4.4, respectively The core under the $3^{\text {rd }}$ surface layer consists of only Au atoms. 


\section{Figure Captions}

Figure 1 Effect of the surface Ag atomic concentration on the rate constant of $\mathrm{CO}$ oxidation, i.e., $k_{\mathrm{CO} 2}$ measured on $\mathrm{Ag} / \mathrm{Au}$ powders and on the NPG. The data on former samples are the same with those published in [23]

Figure 2 Magnitude of Fourier transform of $k^{3}$-weighted EXAFS oscillation extracted from Ag K-edge XAS spectra of the AuAg alloy plates with three different molar compositions: $\mathrm{Ag}_{90} \mathrm{Au}_{10}, \mathrm{Ag}_{50} \mathrm{Au}_{50}$, and $\mathrm{Ag}_{10} \mathrm{Au}_{90}$ (blue, red, and green solid circles connected by lines with respective colors). The results of curve fitting analysis for the three samples performed in the range of $R=1.8-3.2 \AA$ are also depicted (open circles with respective colors).

Figure 3 Magnitude of Fourier transform of $k^{3}$-weighted EXAFS oscillation extracted from Ag K-edge XAS spectrum of the sample of Ag/Au-b (solid blue circles connected with solid line of the same color) and of $\mathrm{Ag}_{2} \mathrm{O}$ (green open circles). The results of curve fitting analysis for $\mathrm{Ag} / \mathrm{Au}-\mathrm{b}$ performed in the range of $R=1.8-3.2 \AA$ are also depicted (open circles with red color).

Figure 4 Model structure around Ag atom exposed on near top surface layers of $\mathrm{Ag} / \mathrm{Au}$ powder and used in the curve fitting analysis of Ag K-edge EXAFS

Open and filled circles stand for $\mathrm{Ag}$ and $\mathrm{Au}$ atoms, respectively.

Figure 5 Variation of the current with time observed during the preparation of NPG by anode etching of $\mathrm{Ag}-\mathrm{Au}$ alloy $(\mathrm{Ag} / \mathrm{Au}=2.5 / 1)$ performed for $90 \mathrm{~min}$ in concentrated nitric acid.

Figure 6 First order plots of the decrease of the reaction mixture of $\mathrm{CO}$ and $\mathrm{O}_{2}$ with a stoichiometric composition and an initial pressure of ca. $2.66 \mathrm{kPa}$ introduced to fresh NPG at:

$\bigcirc$; room temperature, ;283 K, ○; $273 \mathrm{~K}, \triangle$;263 K, $\boldsymbol{\Delta}$;243 K. Dotted line shows $\ln \mathrm{P}_{0} / \mathrm{P}$ at $\mathrm{t}_{1 / 2}$.

Figure 7 Arrhenius plots of $k_{\mathrm{CO} 2}$ measured on:

$\diamond$, NPG;, $\mathrm{Ag} / \mathrm{Au}-\mathrm{b} ; \square, \mathrm{Au} / \mathrm{Ag}(1 / 0.25) ; \square, \mathrm{Au} / \mathrm{Ag}(1 / 1)$ 
Figure 8 HAADF-STEM images of (a) $\mathrm{AuAg} / \mathrm{Al}_{2} \mathrm{O}_{3}(1 / 1)$ and (b) $\mathrm{AuAg} / \mathrm{Al}_{2} \mathrm{O}_{3}(1 / 0.25)$ taken after finishing the catalytic activity measurements for $\mathrm{CO}$ oxidation and respective AuAg particle size distribution diagrams.

Figure 9 Magnitude of Fourier transform of $k^{3}$-weighted EXAFS oscillation extracted

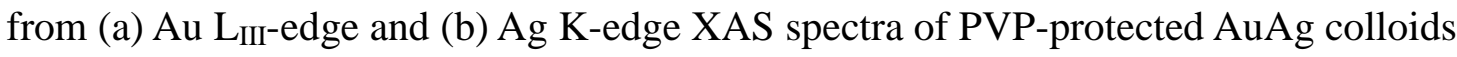
$(\mathrm{Au} / \mathrm{Ag}=1 / 0.25)$ (solid blue circles connected with solid line of the same color). The results of curve fitting analysis performed in the range of $\mathrm{R}=1.95-3.15 \AA$ in the case (a) and 1.6-3.2 $\AA$ in the case (b) are also depicted (open red circles). 
Figure 1 Effect of the surface Ag atomic concentration on the rate constant of $\mathrm{CO}$ oxidation, i.e., $k_{\mathrm{CO} 2}$ measured on $\mathrm{Ag} / \mathrm{Au}$ powders and on the NPG. The data on former samples are the same with those published in [23]

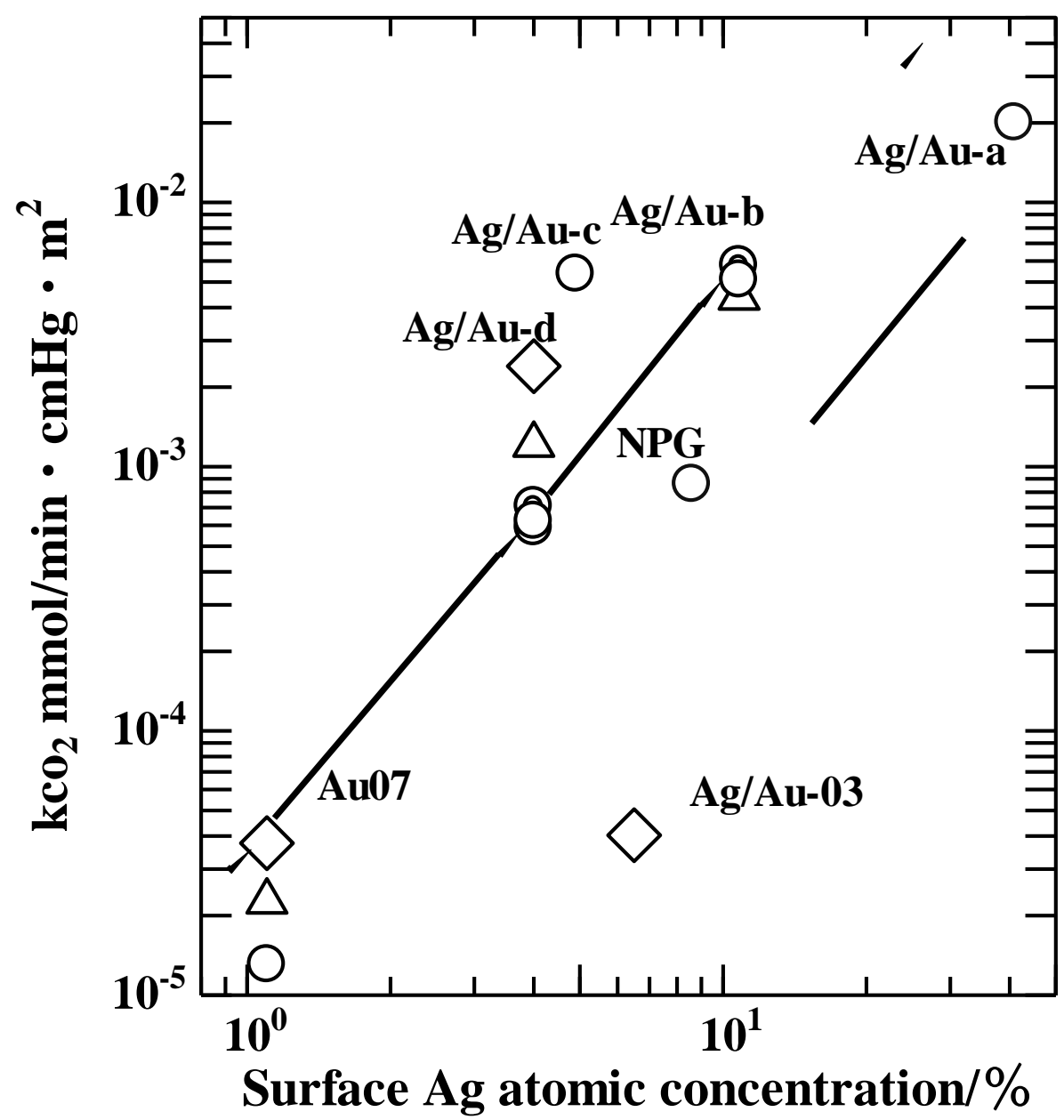

The pretreatment conditions were: $\bigcirc$, oxidation in circulating $\mathrm{O}_{2}$ at $453 \mathrm{~K}$ for $1 \mathrm{~h} ; \triangle$, degassing at $423 \mathrm{~K}$ for $1 \mathrm{~h}$; $\odot$, re-oxidation in $\mathrm{O}_{2}$ at $423 \mathrm{~K}$ for $1 \mathrm{~h}$; $\diamond$, reduction in $\mathrm{H}_{2}$ of $33 \mathrm{kPa}$ at $423 \mathrm{~K}$ for $1 \mathrm{~h}$. 
Figure 2 Magnitude of Fourier transform of $k^{3}$-weighted EXAFS oscillation extracted from Ag K-edge XAS spectra of the AuAg alloy plates with three different molar compositions: $\mathrm{Ag}_{90} \mathrm{Au}_{10}, \mathrm{Ag}_{50} \mathrm{Au}_{50}$, and $\mathrm{Ag}_{10} \mathrm{Au}_{90}$ (blue, red, and green solid circles connected by lines with respective colors). The results of curve fitting analysis for the three samples performed in the range of $R=1.8-3.2 \AA$ are also depicted (open circles with respective colors).

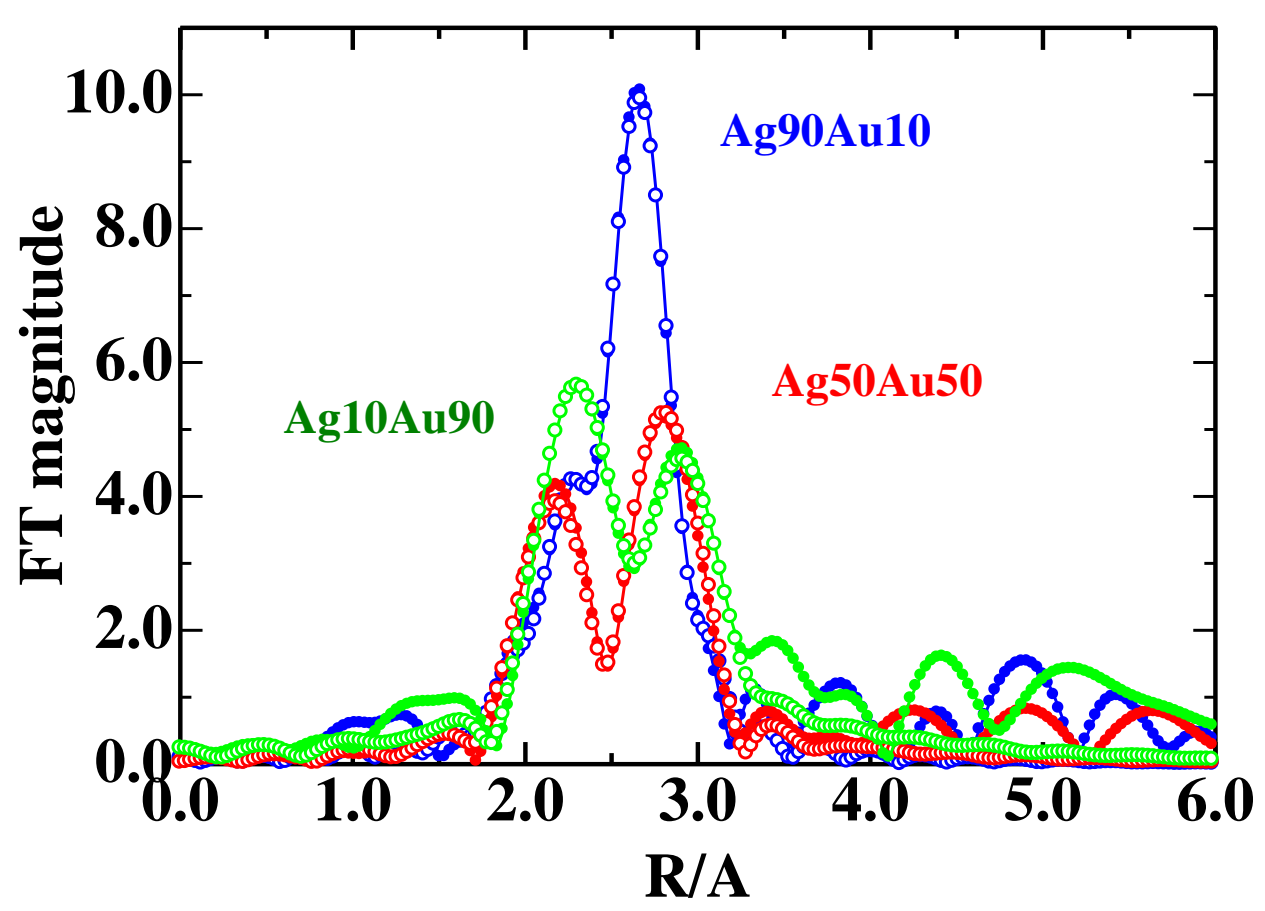


Figure 3 Magnitude of Fourier transform of $k^{3}$-weighted EXAFS oscillation extracted from Ag K-edge XAS spectrum of the sample of Ag/Au-b (solid blue circles connected with solid line of the same color) and of $\mathrm{Ag}_{2} \mathrm{O}$ (green open circles). The results of curve fitting analysis for $\mathrm{Ag} / \mathrm{Au}-\mathrm{b}$ performed in the range of $R=1.8-3.2 \AA$ are also depicted (open circles with red color).

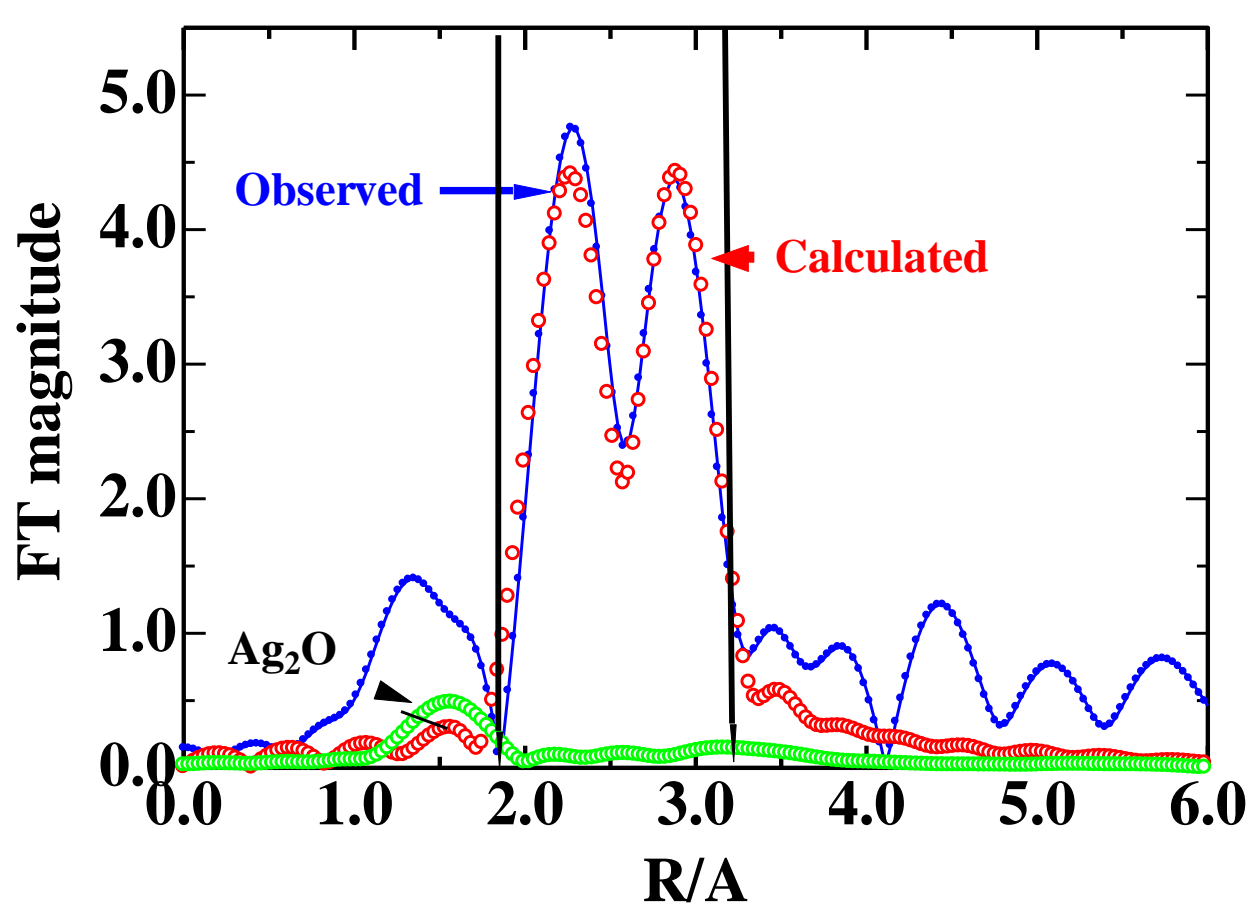


Figure 4 Model structure around $\mathrm{Ag}$ atom exposed on the top surface layer of $\mathrm{Ag} / \mathrm{Au}$ powder and used in the curve fitting analysis of Ag K-edge EXAFS Open and filled circles stand for $\mathrm{Ag}$ and $\mathrm{Au}$ atoms, respectively.

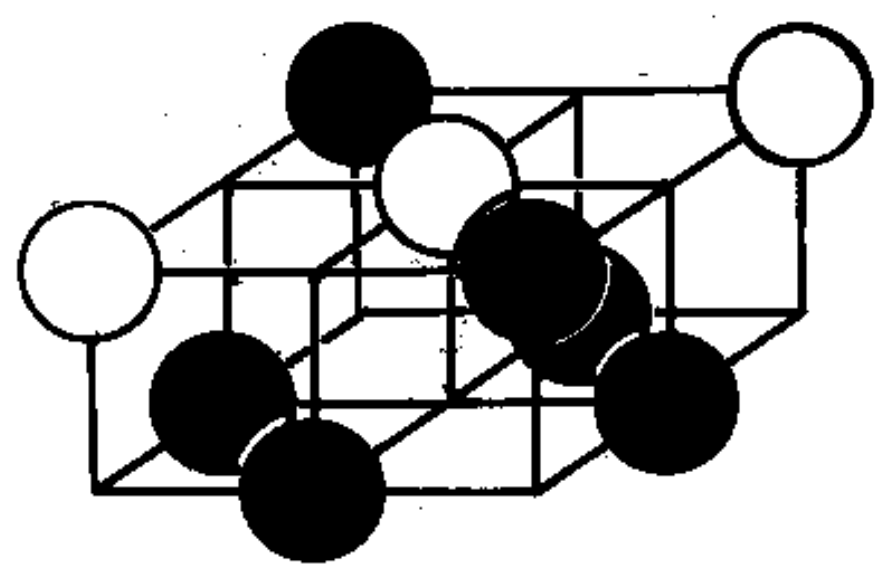


Figure 5 Variation of the current with time observed during the preparation of NPG by anode etching of $\mathrm{Ag}-\mathrm{Au}$ alloy $(\mathrm{Ag} / \mathrm{Au}=2.5 / 1)$ performed for $90 \mathrm{~min}$ in concentrated nitric acid.

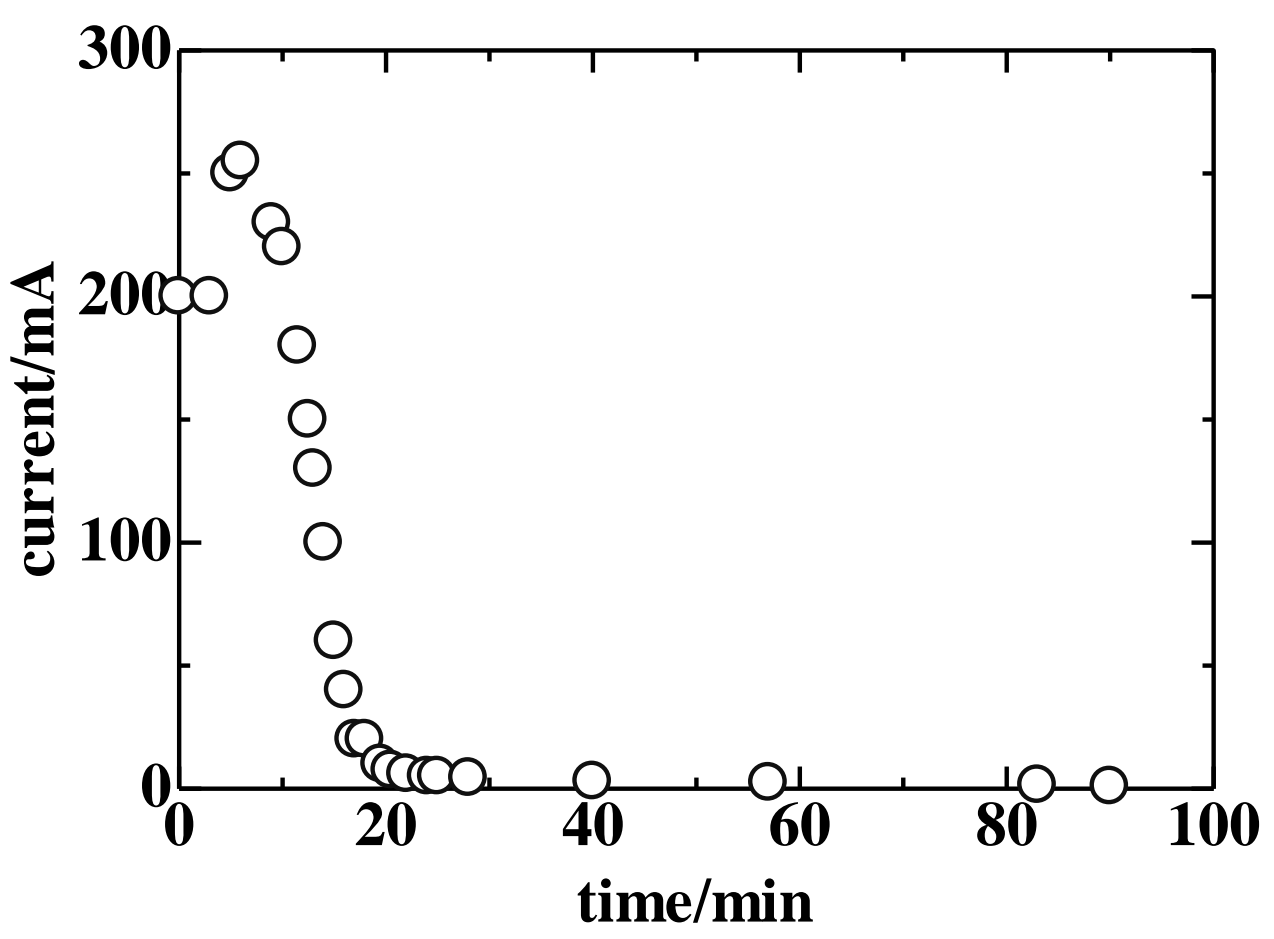


Figure 6 First order plots of the decrease of the reaction mixture of $\mathrm{CO}$ and $\mathrm{O}_{2}$ with a stoichiometric composition and an initial pressure of ca. $2.66 \mathrm{kPa}$ introduced to fresh NPG at:

$\bigcirc$;room temperature, $\bigcirc ; 283 \mathrm{~K}$, ○; $273 \mathrm{~K}, \triangle$;263 K, $\boldsymbol{\Delta}$;243 K. Dotted line shows $\ln \mathrm{P}_{0} / \mathrm{P}$ at $\mathrm{t}_{1 / 2}$.

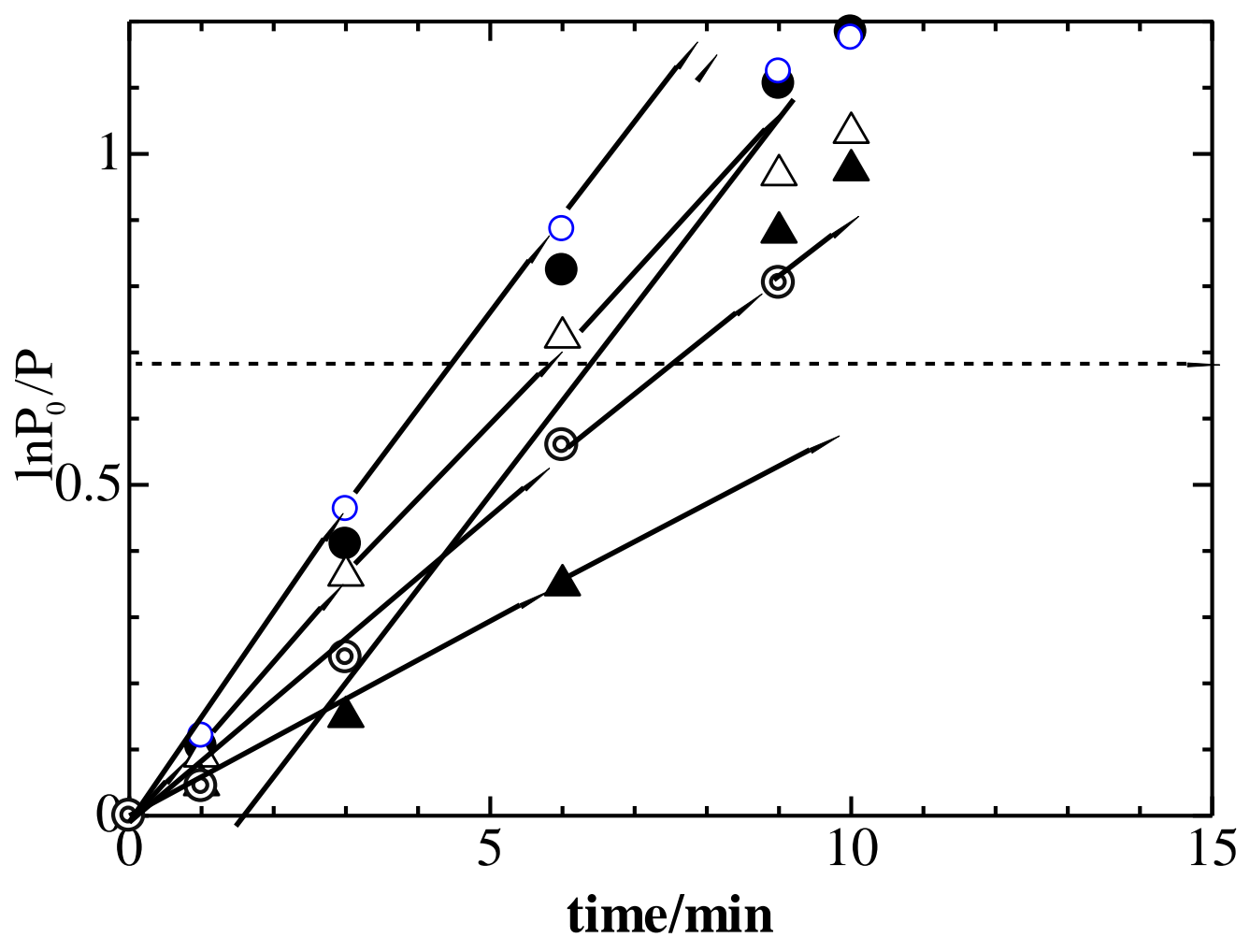


Figure 7 Arrhenius plots of $k_{\mathrm{CO} 2}$ measured on:

$\diamond, \mathrm{NPG} ; \bigcirc, \mathrm{Ag} / \mathrm{Au}-\mathrm{b} ; \square, \mathrm{Au} / \mathrm{Ag}(1 / 0.25) ; \square, \mathrm{Au} / \mathrm{Ag}(1 / 1)$

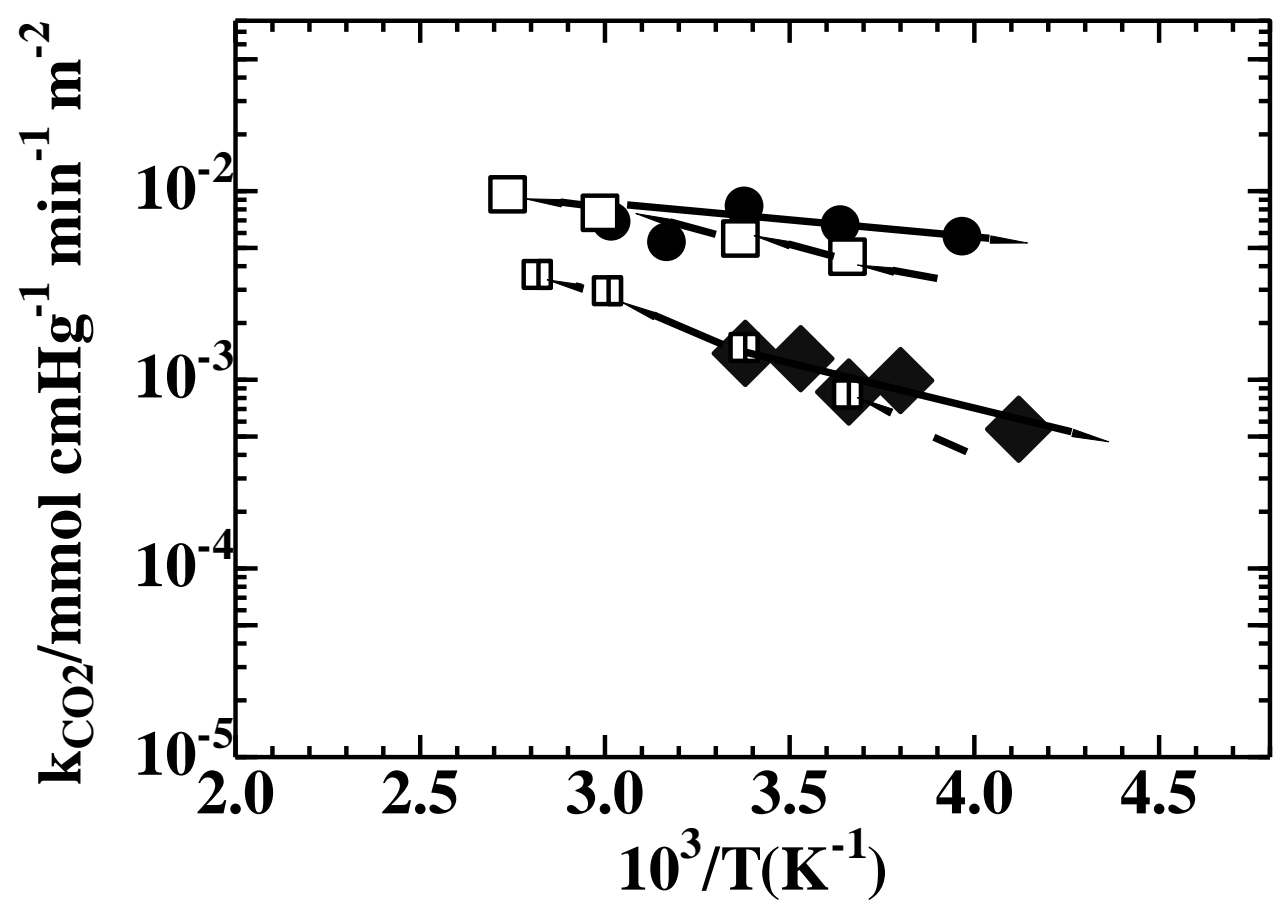


Figure 8 HAADF-STEM images of (a) $\mathrm{AuAg} / \mathrm{Al}_{2} \mathrm{O}_{3}$ (1/1) and (b) $\mathrm{AuAg} / \mathrm{Al}_{2} \mathrm{O}_{3}(1 / 0.25)$ taken after finishing the catalytic activity measurements for $\mathrm{CO}$ oxidation and respective AuAg particle size distribution diagrams.

(a)
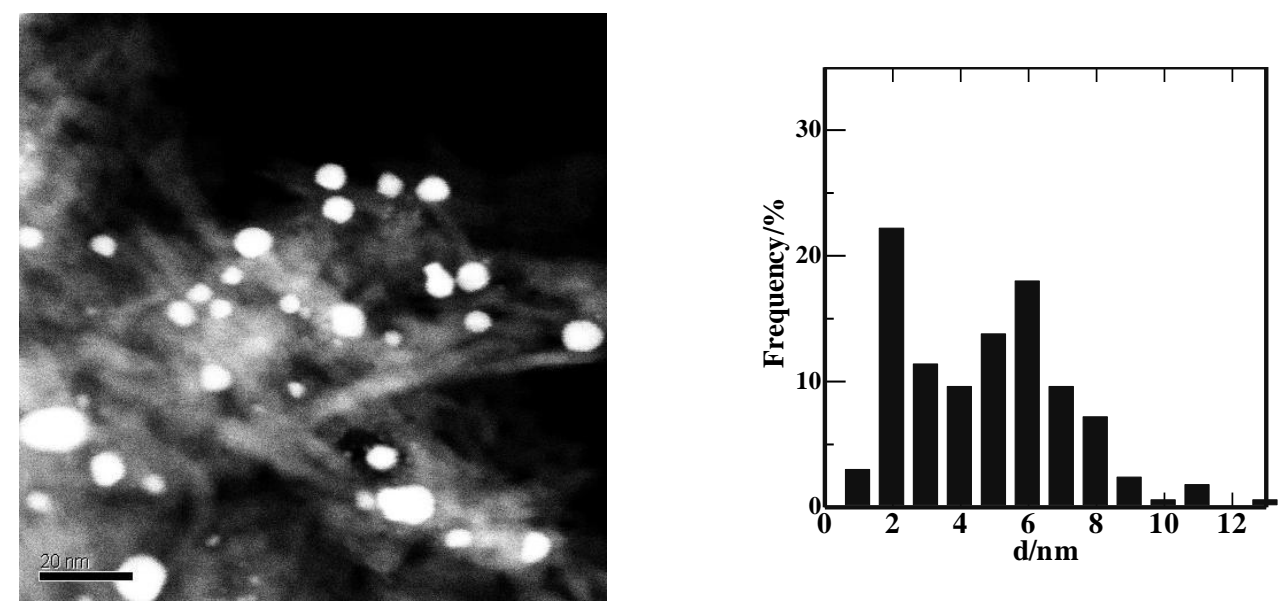

(b)
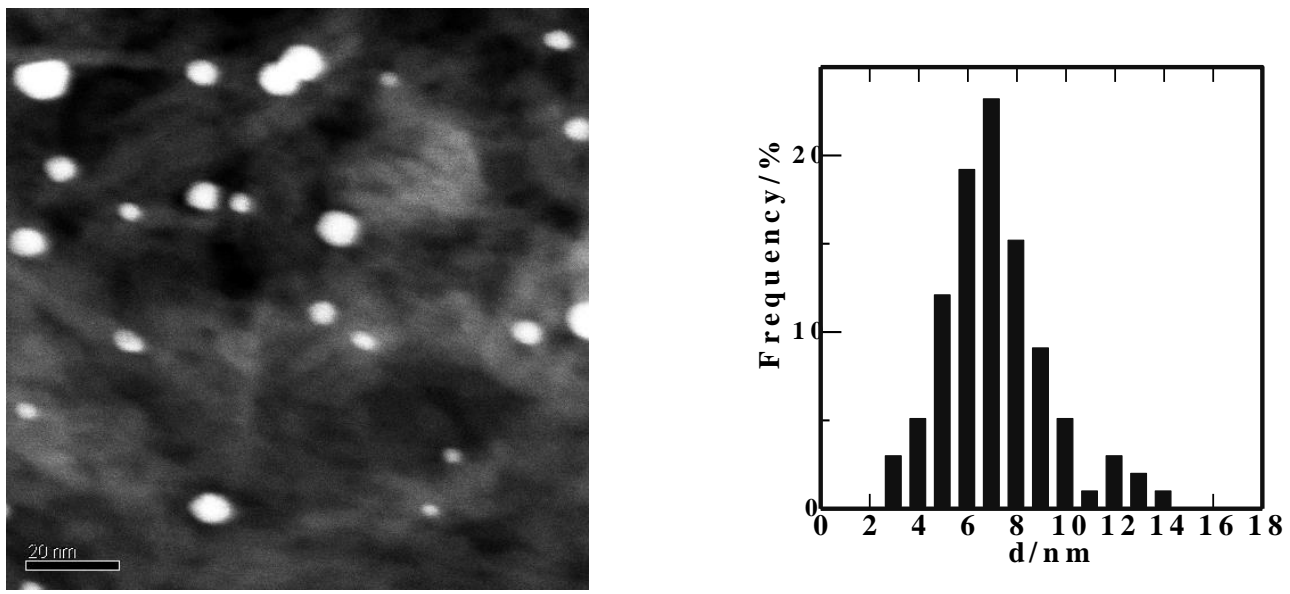
Figure 9 Magnitude of Fourier transform of $k^{3}$-weighted EXAFS oscillation extracted

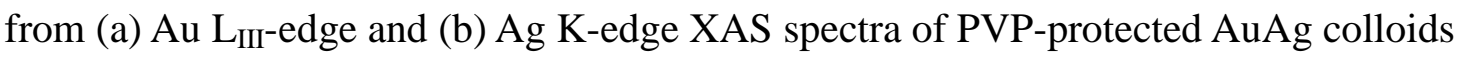
( $\mathrm{Au} / \mathrm{Ag}=1 / 0.25)$ (solid blue circles connected with solid line of the same color). The results of curve fitting analysis performed in the range of $\mathrm{R}=1.95-3.2 \AA$ in the case (a) and 1.6-3.2 $\AA$ in the case (b) are also depicted (open red circles).

(a)

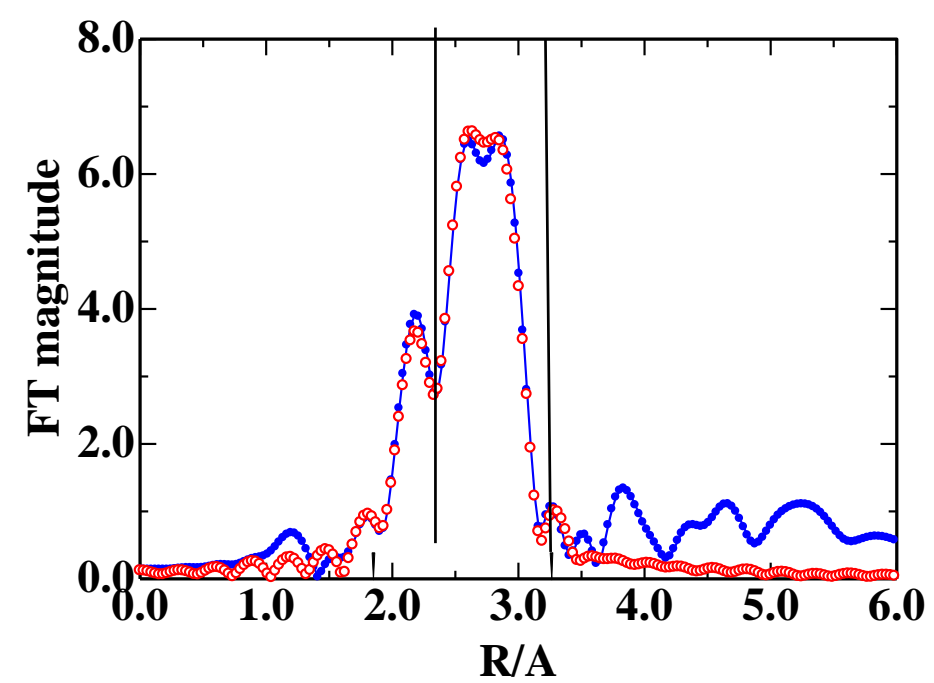

(b)

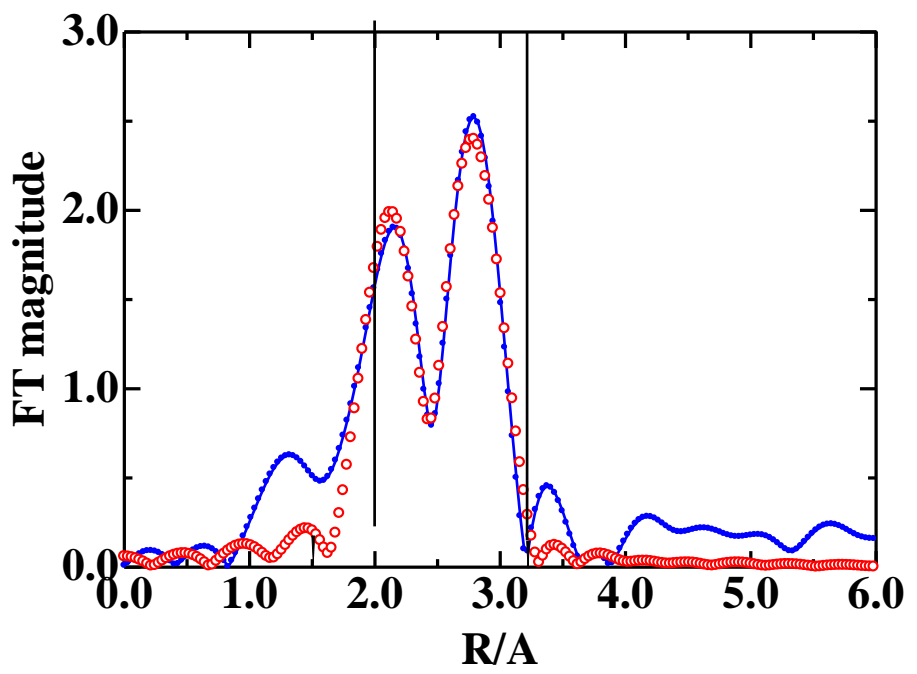


Graphical Abstract

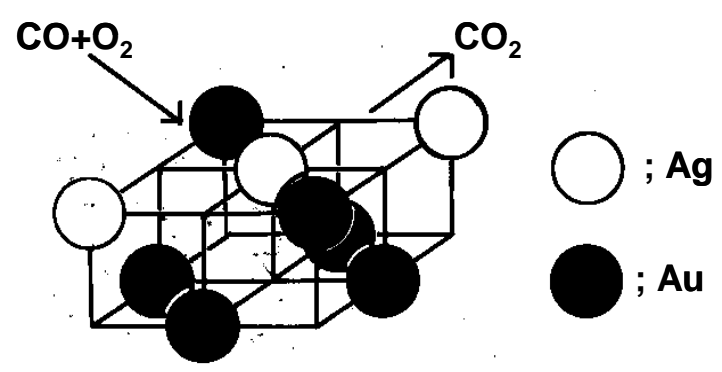

